Check for updates

Cite this: J. Mater. Chem. A, 2021, 9, 25114

Received 28th June 2021

Accepted 29th October 2021

DOI: $10.1039 / \mathrm{d} 1 \mathrm{ta0} 05457 \mathrm{k}$

rsc.li/materials-a

\section{Exploiting the flexibility of the pyrochlore composition for acid-resilient iridium oxide electrocatalysts in proton exchange membranes $\uparrow$}

\author{
David L. Burnett, (D) a Enrico Petrucco, (DD b Reza J. Kashtiban, ${ }^{\mathrm{c}}$ Stewart F. Parker, (D) d \\ Jonathan D. B. Sharman ${ }^{\mathrm{b}}$ and Richard I. Walton (iD *a
}

\section{Introduction}

The electrocatalytic oxidation of water to oxygen is a key process in developing future devices for various energy-related applications that are much sought after for sustainable, clean production and storage of electricity or fuels. The oxygen evolution reaction (OER) is a major limiting step in improving the efficiency in such applications since it inherently possesses unfavourable thermodynamics, being a four-electron transfer reaction. ${ }^{1}$ OER in aqueous acid electrolytes is desirable since it provides high current densities and high voltage efficiency, and in proton exchange membrane devices the fast kinetics of the partnering hydrogen evolution reaction are beneficial. ${ }^{2}$ Furthermore, contamination by aerial $\mathrm{CO}_{2}$ and precipitation of carbonates is avoided, which is not the case for alkaline electrolytes. These benefits are exploited in proton-exchange

${ }^{a}$ Department of Chemistry, University of Warwick, Gibbet Hill Road, Coventry CV4 7AL, UK. E-mail: r.i.walton@warwick.ac.uk

${ }^{b} J o h n s o n$ Matthey Technology Centre, Blounts Court, Sonning Common, Reading, RG4 9NH, UK

'Department of Physics, University of Warwick, Gibbet Hill Road, Coventry CV4 7AL, $U K$

${ }^{d}$ ISIS Facility, STFC Rutherford Appleton Laboratory, Didcot, OX11 OQX, Oxon, UK $\dagger$ Electronic supplementary information (ESI) available. See DOI: $10.1039 / \mathrm{d} 1 \mathrm{ta} 05457 \mathrm{k}$ membrane (PEM) devices that make use of proton-conducting polymer electrolytes, such as in electrolysers for water splitting. ${ }^{3}$ In PEM fuel cells an OER electrocatalyst can be used to mitigate the carbon corrosion reaction that may occur under specific conditions of fuel starvation or other excursions to high electrode potentials. ${ }^{4}$

Acid resistant electrocatalysts are in high demand and presently the most promising materials are oxides of platinum group metals, such as ruthenium and iridium. ${ }^{5}$ The rutiles $\mathrm{RuO}_{2}$ and $\mathrm{IrO}_{2}$ and solid-solutions thereof can be considered benchmark materials in this respect. ${ }^{6}$ Precious-metal-free materials may be desirable, ${ }^{7}$ and although manganese oxides have recently been suggested as alternatives that have been claimed to operate over a range of $\mathrm{pH},{ }^{8}$ iridium and ruthenium oxides remain the most active and robust materials for OER under acidic conditions. One strategy to overcome the use of expensive and limited precious metals is to use complex ternary oxides with the precious metal diluted by the presence of a nonprecious metal. More than 25 years ago ten Kortenaar et al. studied a range of ternary iridium oxides for their activity towards OER, ${ }^{9}$ and although they found no correlation between crystal structure and activity, they discovered some materials with promising properties including those with pyrochlore and fluorite structures. Earlier, Goodenough and co-workers had made a detailed study of the electrocatalytic properties of complex pyrochlores $\mathrm{Pb}_{2}\left(\mathrm{Ir}_{2-x} \mathrm{~Pb}_{x}\right) \mathrm{O}_{7-y}$ and $\mathrm{Pb}_{2}\left(\mathrm{Ru}_{2-x} \mathrm{~Pb}_{x}\right) \mathrm{O}_{7-y}$ 
as a function of $\mathrm{pH}$ and proposed that surface oxide vacancies provide binding sites for water. ${ }^{10}$ With the resurgence of interest in electrocatalysts for OER, recent work has focussed on discovery of new acid-stable, and highly active iridium oxides with an emphasis on thrifting of precious metals, as well as finding more robust materials: this includes strontium iridium oxides derived from thin films ${ }^{11}$ and on various perovskites, including double perovskites, ${ }^{12}$ triple perovskites, ${ }^{13}$ iridiumdoped strontium titanate, ${ }^{14}$ hexagonal perovskites, ${ }^{15}$ and layered Ruddlesden-Popper type structures. ${ }^{16}$ Many of these emerging materials have activities and stabilities that are apparently superior to binary iridium oxides.

Oxide materials with the $\mathrm{A}_{2} \mathrm{~B}_{2} \mathrm{O}_{6} \mathrm{O}^{\prime}$ pyrochlore structure ${ }^{17}$ stand out as being of interest for heterogeneous catalysis applications. There are a variety of combinations of possible A and B metals, and oxygen non-stoichiometry is possible by partial occupation of the $\mathrm{O}^{\prime}$ site, or replacement by hydroxide or water leading to inherently defective materials with redox properties for the B-site metal and pathways for oxide-ion migration, or proton conduction, in the solid-state. Furthermore, pyrochlore oxides can be crystallised easily from water under hydrothermal conditions to give fine (often nanoscale) powders ${ }^{18}$ that can be fabricated into catalyst layers. Partnering iridium on the B site with a range of A-site metals offers the possibility of tuning crystal chemistry, electronic structure and potentially surface chemistry to optimise electrocatalysis properties. ${ }^{19}$ We have previously described the electrocatalytic activity of the pyrochlore $\mathrm{Bi}_{2} \mathrm{Ir}_{2} \mathrm{O}_{7}$, prepared via a facile hydrothermal route, ${ }^{20}$ and the mixed ruthenate-iridate phases $\left(\mathrm{Na}_{0.33} \mathrm{Ce}_{0.67}\right)_{2}\left(\mathrm{Ir}_{1-x} \mathrm{Ru}_{x}\right)_{2} \mathrm{O}_{7} \cdot{ }^{21}$ Sun et al. compared the OER activity of the pyrochlores $\mathrm{Bi}_{2} \mathrm{Ir}_{2} \mathrm{O}_{7}$ and $\mathrm{Pb}_{2} \mathrm{Ir}_{2} \mathrm{O}_{6.5}$ with $\mathrm{IrO}_{2}$ and proposed a correlation of activity with the local atomic distortion of iridium coordination. ${ }^{22}$ Lebedev et al. prepared $\mathrm{Y}_{2} \mathrm{Ir}_{2} \mathrm{O}_{7}$, $\mathrm{Bi}_{2} \mathrm{Ir}_{2} \mathrm{O}_{7}$ and $\mathrm{Pb}_{2} \mathrm{Ir}_{2} \mathrm{O}_{7}$, including mixed A-site variants of these end members, and produced electrocatalysts with OER activities approaching that of $\mathrm{IrO}_{2}$ nanoparticles in acid conditions, ${ }^{23}$ Shang et al. studied $\mathrm{R}_{2} \mathrm{Ir}_{2} \mathrm{O}_{7}(\mathrm{R}=\mathrm{Ho}, \mathrm{Tb}, \mathrm{Gd}, \mathrm{Nd}, \mathrm{Pr})$ and proposed that $\operatorname{Pr}_{2} \mathrm{Ir}_{2} \mathrm{O}_{7}$ was most active due to enhanced covalency in Ir-O bonds and a higher conductivity, ${ }^{24}$ and Abbot et al. compared the reactivity of iridate pyrochlores with ruthenate analogues. ${ }^{25}$ The pyrochlores are also active in alkali conditions: Parrondo et al. studied $\mathrm{A}_{2} \mathrm{~B}_{2} \mathrm{O}_{7-y}(\mathrm{~A}=\mathrm{Pb}$ or $\mathrm{B}$, and $\mathrm{B}=\mathrm{Ru}$, Ir or Os) for OER and correlated activity with composition. ${ }^{26}$

Here we explore new variants of pyrochlore iridates, $(\mathrm{Na}, \mathrm{Ca})_{2-x}\left(\mathrm{Ir}_{2-y} \mathrm{M}_{y}\right) \mathrm{O}_{6} \cdot n \mathrm{H}_{2} \mathrm{O}(\mathrm{M}=\mathrm{Sb}, \mathrm{Zr}, \mathrm{Ru}, \mathrm{Rh})$, with the aim of providing robust new electrocatalyst materials, stable in acid conditions and with lower PGM content than conventional $\mathrm{IrO}_{2}-$ based materials. We were also interested to study materials with A-site cations of lower charge than the lanthanides that others have recently focussed upon. Furthermore, we avoided possible complications of the conceivable redox chemistry of $\mathrm{Ce}, \mathrm{Pb}$ or $\mathrm{Bi}$, which were earlier used as A-site cations, and that may therefore potentially result in some instability of the system. We instead studied materials with A-site $\mathrm{Ca}$ and $\mathrm{Na}$, and also investigate the effect of inclusion of dopant cations on the $\mathrm{B}$ site. We first prove their use in real devices, by making measurements in membrane electrode assemblies (MEAs), designed for fuel cell applications where the OER electrocatalyst is present to evolve oxygen under abnormal operating conditions, at extremes of potential, to avoid carbon corrosion. We then focus on understanding the stability of the iridate pyrochlores in aqueous acid, and how leaching of metal cations can be charge compensated, since this issue remains unresolved in the literature. Our work illustrates the benefit of the compositional flexibility of the pyrochlore structure for design of OER catalysts: from the stoichiometry of the phase synthesised, to ion-exchange for stabilising materials under acid conditions via protonation to achieve charge balance.

\section{Results and discussion}

\section{Characterisation of pyrochlore electrocatalysts}

Powder neutron diffraction was used to determine the composition and crystal structure of the new pyrochlores prepared in this work due to the sensitivity of the method to oxygen positions in the presence of high atomic number metals (such as Ir) and the possibility of detecting the protons of any occluded water molecules, which would be very challenging using X-ray diffraction methods. The parent material $(\mathrm{Ca}, \mathrm{Na})_{2-x} \mathrm{Ir}_{2} \mathrm{O}_{6} \cdot n \mathrm{H}_{2}-$ $\mathrm{O}$, which we have recently studied using X-ray absorption spectroscopy, ${ }^{27}$ is related to the phase $\left(\mathrm{Na}_{0.27} \mathrm{Ca}_{0.59}\right)_{2^{-}}$ $\mathrm{Ir}_{2} \mathrm{O}_{6} \cdot 0.66 \mathrm{H}_{2} \mathrm{O}$ which we reported earlier, ${ }^{28}$ but since we have optimised the synthesis method to prepare better crystalline materials free of $\mathrm{IrO}_{2}$ impurity (by replacing the $\mathrm{Ca}\left(\mathrm{NO}_{3}\right)_{2} \cdot 4 \mathrm{H}_{2} \mathrm{O}$ earlier used by $\mathrm{CaO}_{2}$ ) we performed a full analysis of its structure to compare with the earlier phase. A material prepared in the absence of $\mathrm{Na}$ is a novel variant of the iridate pyrochlore and was prepared for comparison of its electrochemical properties. Fig. 1a and $\mathrm{b}$ show the final Rietveld fit to the powder neutron data and Table 1 shows the fitted crystallographic parameters for these two materials. Proton positions of water molecules were added on $32 \mathrm{e}$ sites at $\sim 1 \AA$ from the $8 \mathrm{~b}$ oxygens, based on the model used by Dickens and Weller for hydrated tantalate pyrochlore, ${ }^{29}$ and then allowed to refine with anisotropic thermal parameters.

The refined cubic lattice parameter of the $(\mathrm{Ca}, \mathrm{Na})_{2-x} \mathrm{Ir}_{2} \mathrm{O}_{6}-$ $\cdot n \mathrm{H}_{2} \mathrm{O}$ material (10.2156(1) $\AA$ ) is slightly smaller than reported for the analogous material prepared earlier from different reagents $(10.2589(1) \AA),{ }^{28}$ and this is consistent with the different occupancy of the $\mathrm{O}^{\prime}$ oxygen site implying a different hydration level, even though the composition of the oxide framework is essentially identical. The correct charge balance is confirmed using bond valence sums using the refined crystal structure interatomic distances: this gives a value of average Ir oxidation state of 4.71 , consistent with the value of 4.52 implied by the chemical formula above (see below for further discussion of Ir oxidation state from XANES spectroscopy). Charge balance means that the oxygens on the $\mathrm{O}^{\prime}$ site belong to water molecules, and their associated protons were refined in the neutron data fitting using the model reported by Dickens and Weller for hydrated tantalate pyrochlores ${ }^{29}$ (see Table 1 ). The sodium-free material, prepared using $\mathrm{Li}_{2} \mathrm{O}_{2}$ as oxidant in $\mathrm{KOH}$ as mineraliser, is successfully modelled with only $\mathrm{Ca}$ on the A-site: there is no evidence for the presence of $\mathrm{K}$ or $\mathrm{Li}$ in the materials and their 

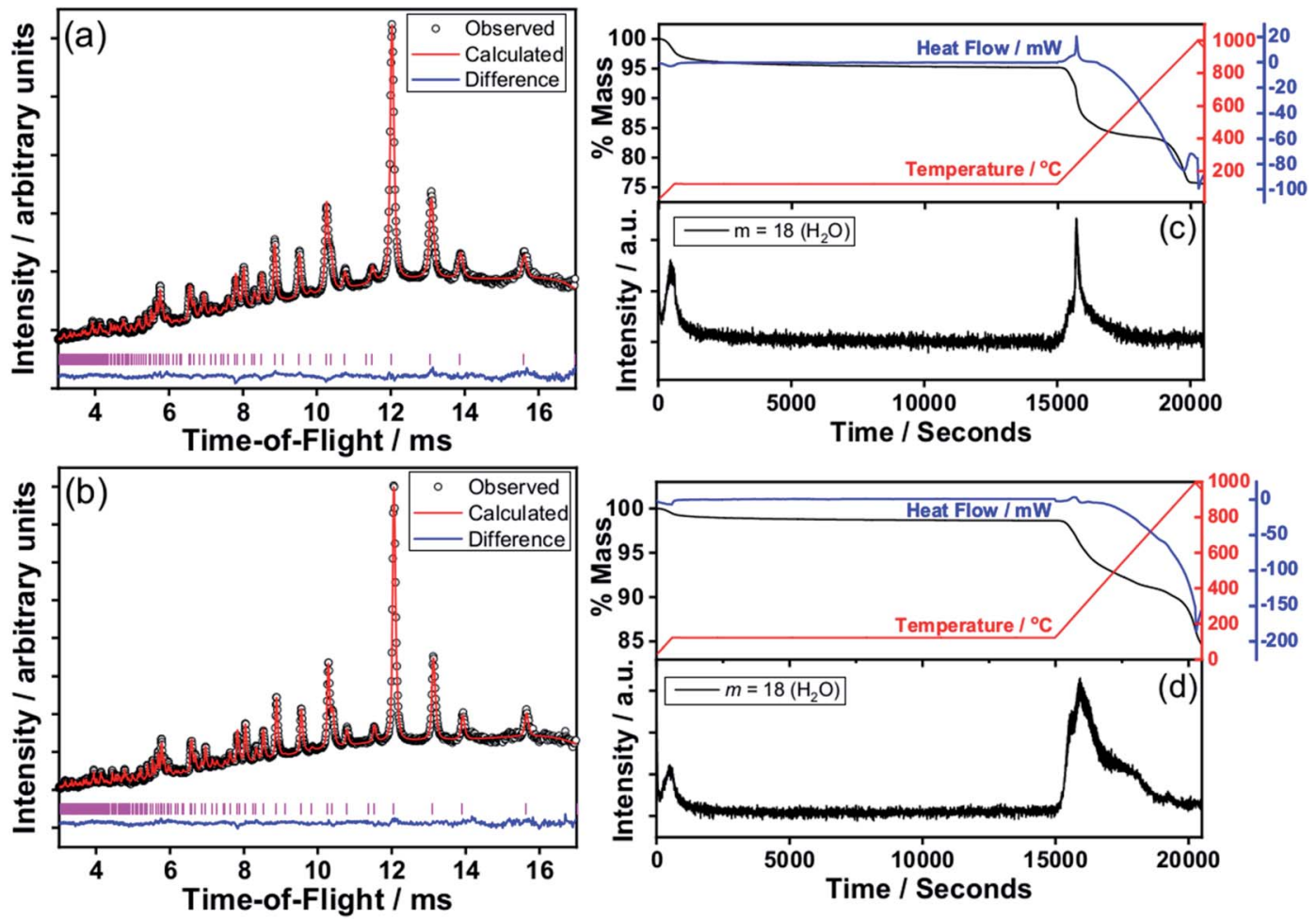

Fig. 1 Characterisation data from iridate pyrochlores: (a) and (b) show plots of the Rietveld refinement against neutron patterns (bank 5, GEM) of $(\mathrm{Ca}, \mathrm{Na})_{2-x} \mid \mathrm{r}_{2} \mathrm{O}_{6} \cdot n \mathrm{H}_{2} \mathrm{O}$ and the sodium-free analogue $\mathrm{Ca}_{2-x} \mid \mathrm{r}_{2} \mathrm{O}_{6} \cdot n \mathrm{H}_{2} \mathrm{O}$, respectively. Pink tick marks show the positions of allowed Bragg peaks (space group Fd3m; see Table 1 for refined structural parameters). (c) and (d) show TGA-DSC-MS from $\left(\mathrm{Ca}_{1}, \mathrm{Na}_{2-x} \mathrm{Ir}_{2} \mathrm{O}_{6} \cdot n \mathrm{H}_{2} \mathrm{O}\right.$ and $\mathrm{Ca} a_{2-x} \mathrm{Ir} \mathrm{r}_{2}-$ $\mathrm{O}_{6} \cdot \mathrm{nH}_{2} \mathrm{O}$ pyrochlores showing the presence of both surface and crystal water (see text for discussion).

Table 1 Refined structural parameters for $(\mathrm{Ca}, \mathrm{Na})_{2-x} \mid r_{2} \mathrm{O}_{6} \cdot n \mathrm{H}_{2} \mathrm{O}$ and variant $\mathrm{Ca}_{2-x} \mathrm{Ir}_{2} \mathrm{O}_{6} \cdot n \mathrm{H}_{2} \mathrm{O}$ refined from Rietveld analysis of powder neutron diffraction data

\begin{tabular}{lllllll}
\hline Atom & Site & $x$ & $y$ & $z$ & Occ & $U_{\text {iso }} / \AA^{2}$ \\
\hline \multicolumn{7}{l}{$(\mathbf{C a}, \mathbf{N a})_{2-\boldsymbol{x}} \mathbf{I r}_{2} \mathbf{O}_{\mathbf{6}} \cdot \boldsymbol{n} \mathbf{H}_{\mathbf{2}} \mathbf{O}: \boldsymbol{a}=\mathbf{1 0 . 2 1 5 6}(\mathbf{1}) \AA$} \\
$\mathrm{Ca}$ & $16 \mathrm{~d}$ & 0.5 & 0.5 & 0.5 & $0.597(6)$ & $0.0127(6)$ \\
$\mathrm{Na}$ & $16 \mathrm{~d}$ & 0.5 & 0.5 & 0.5 & $0.267(5)$ & $0.0127(6)$ \\
$\mathrm{Ir}$ & $16 \mathrm{c}$ & 0 & 0 & 0 & $1.000(1)$ & $0.00940(12)$ \\
$\mathrm{O}$ & $48 \mathrm{f}$ & $0.3244(1)$ & 0.125 & 0.125 & $1.000(2)$ & $0.00827(12)$ \\
$\mathrm{O}^{\prime}$ & $8 \mathrm{~b}$ & 0.375 & 0.375 & 0.375 & $0.950(7)$ & $0.0282(10)$ \\
$\mathrm{H}$ & $32 \mathrm{e}$ & 0.3289 & 0.3289 & 0.3289 & $0.476(14)$ & $a$
\end{tabular}

$\mathrm{Ca}_{2-x} \mathrm{Ir}_{2} \mathrm{O}_{6} \cdot n \mathrm{H}_{2} \mathrm{O}: a=10.24071(14) \AA$

$\begin{array}{lllllll}\mathrm{Ca} & 16 \mathrm{~d} & 0.5 & 0.5 & 0.5 & 0.741(7) & 0.0136(6) \\ \mathrm{Ir} & 16 \mathrm{c} & 0 & 0 & 0 & 1.000(2) & 0.00729(11) \\ \mathrm{O} & 48 \mathrm{f} & 0.3247(2) & 0.125 & 0.125 & 1.000(3) & 0.00804(12) \\ \mathrm{O}^{\prime} & 8 \mathrm{~b} & 0.375 & 0.375 & 0.375 & 1.001(12) & 0.0342(11) \\ \mathrm{H} & 32 \mathrm{e} & 0.3289 & 0.3289 & 0.3289 & 0.50(4) & b\end{array}$

${ }^{a} U_{11}=0.76(3), U_{22}=0.30(3), U_{33}=0.76(3), U_{12}=-0.253(19), U_{13}=$ $-0.40(2), U_{23}=-0.253(19) .{ }^{b} U_{11}=0.799(8), U_{22}=0.345(8), U_{33}=$ $0.799(8), U_{12}=-0.269(4), U_{13}=-0.391(4), U_{23}=-0.269(4)$.

inclusion in the Rietveld fitting had a detrimental effect on the fit parameter. The lattice parameter of this material, $a=$ 10.24071(14) $\AA$, is rather similar to the two values discussed above for different samples of the mixed $\mathrm{Na}$, Ca A-site material, suggesting essentially the same structure for the materials with the A-site cations having little effect on the iridium oxide framework of the structure. The bond valence sum for iridium in this composition is 4.64 , which is close to the value expected for charge balance of 4.52 for the refined chemical formula $\left(\mathrm{Ca}_{0.74}\right)_{2} \mathrm{Ir}_{2} \mathrm{O}_{6} \cdot 0.95 \mathrm{H}_{2} \mathrm{O}$.

The presence of crystal water in the pyrochlores is also evidenced by TGA-DSC-MS, Fig. 1c and d, which shows water loss at $200-400{ }^{\circ} \mathrm{C}$, distinct from surface water that is lost at lower temperature as it is an exothermic rather than an endothermic event. To ensure all surface water was removed the TGA-DSC-MS data were recorded in two stages of heating, with a dwell of several hours at $100{ }^{\circ} \mathrm{C}$ before heating to higher temperature. The mass loss due to crystal water from (Ca,Na) $)_{2-x} \mathrm{Ir}_{2} \mathrm{O}_{6} \cdot n \mathrm{H}_{2} \mathrm{O}$ corresponds to $3.6 \%$ which is similar to the $3.2 \%$ loss expected if the $\mathrm{O}^{\prime}$ site is fully occupied by $\mathrm{H}_{2} \mathrm{O}$, while for the $\mathrm{Ca}_{2-x} \mathrm{Ir}_{2}-$ $\mathrm{O}_{6} \cdot n \mathrm{H}_{2} \mathrm{O}$ material the $3.0 \%$ mass loss is similar to the $3.2 \%$ if the $\mathrm{O}^{\prime}$ site is fully occupied by $\mathrm{H}_{2} \mathrm{O}$. Thermodiffractometry (ESI $\dagger$ ) shows the $(\mathrm{Ca}, \mathrm{Na})_{2-x} \mathrm{Ir}_{2} \mathrm{O}_{6} \cdot n \mathrm{H}_{2} \mathrm{O}$ pyrochlore to be stable to $\sim 600{ }^{\circ} \mathrm{C}$ when collapse to Ir metal and $\mathrm{Ca}_{2} \mathrm{IrO}_{4}$ is seen, which would explain the additional mass loss seen in the TGA at higher temperatures. In contrast, $\mathrm{Ca}_{2-x} \mathrm{Ir}_{2} \mathrm{O}_{6} \cdot n \mathrm{H}_{2} \mathrm{O}$ is somewhat more stable with powder XRD showing no structural collapse until above $800{ }^{\circ} \mathrm{C}$.

The effect of synthesis temperature and $\mathrm{NaOH}$ concentration on the materials produced was investigated (ESI $\dagger$ ). Lowering the synthesis temperature to $170{ }^{\circ} \mathrm{C}$ or the concentration of $\mathrm{NaOH}$ to $5 \mathrm{M}$ gave materials with a broader diffraction profile, 
indicative of smaller crystallite domain size. Partial substitution of some of the iridium in the parent $(\mathrm{Ca}, \mathrm{Na})_{2-x} \mathrm{Ir}_{2} \mathrm{O}_{6} \cdot n \mathrm{H}_{2} \mathrm{O}$ pyrochlore by a tetravalent or pentavalent cation was investigated to give materials $(\mathrm{Ca}, \mathrm{Na})_{2-x}\left(\mathrm{Ir}_{2-y} \mathrm{M}_{y}\right) \mathrm{O}_{6} \cdot n \mathrm{H}_{2} \mathrm{O}$. We considered that this might have the effect of (i) adjusting the average oxidation state of iridium, (ii) expanding or contracting the pyrochlore unit cell, (iii) distorting the average coordination about the B site and (iv) diluting the amount of precious metal in the material, or combinations thereof. Table 2 shows the phase-pure pyrochlores thus produced, with characterisation data presented in the ESI. $\dagger$ For Sb as B-site substituent a solidsolution is formed with lattice parameters showing an expansion of the lattice consistent with the incorporation of the larger $\mathrm{Sb}^{5+}$ ion (as proven by $\mathrm{Sb}$ K-edge X-ray absorption near-edge structure (XANES), see ESI $\dagger$ ): octahedral $\operatorname{Ir}(\mathrm{Iv}) 0.625 \AA$ and $\operatorname{Ir}(\mathrm{v})$ $0.57 \AA$ being smaller than octahedral $\mathrm{Sb}(\mathrm{v}) 0.6 \AA{ }^{30}{ }^{30}$ For $\mathrm{Zr}$, there is also a solubility limit since above $y=0.5$, the phase $\mathrm{CaZr}_{4} \mathrm{O}_{9}$ crystallises as a by-product. For $y \leq 0.5$ the pyrochlore lattice is expanded, although not by as much as might be expected for inclusion of six-coordinate $\mathrm{Zr}^{4+}(0.72 \AA)$, but a full analysis of powder neutron data from the phase with $y=0.5$ reveals that some of the zirconium is present on the A-site as well as the Bsite (ESI $\dagger$ ). The inclusion of Ru leads to a complete solid solution, but with a contraction of the cubic lattice with increasing $\mathrm{Ru}$ content. This is consistent with recent work on mixed iridium-ruthenium pyrochlores of some lanthanides. ${ }^{31}$ XANES analysis at the Ru K-edge (ESI $\dagger$ ) shows that both metals have an average oxidation state close to +4.5 , so the smaller size of $\mathrm{Ru}^{4+}$ and $\mathrm{Ru}^{5+}$ compared to the $\mathrm{Ir}^{4+/ 5+}$ must be responsible for the lattice contraction. In the case of Rh, only smaller amounts can be substituted, up to $y=0.3$, with evidence of a lattice expansion: this would be consistent with the larger size of $\mathrm{Rh}^{3+}$ or $\mathrm{Rh}^{4+}$, and the difficulty in oxidising $\mathrm{Rh}$ to the higher oxidation state may be the reason why only a limited amount can be included in the structure.

For all of the pyrochlores studied analysis of Ir $\mathrm{L}_{\mathrm{III}}$-edge XANES spectra shows that the oxidation state of Ir is close to +4.5 , Fig. 2 . This is consistent with the refined crystal structures of the pure iridium materials (see above) and for the B-site substituted materials shows that any charge imbalance brought about by the inclusion of a pentavalent $\mathrm{Sb}^{5+}$ or tetravalent $\mathrm{Zr}^{4+}$ cation can presumably be accounted for by adjustment of the $\mathrm{Na}^{+} / \mathrm{Ca}^{2+}$ population of the A-site to maintain the Ir oxidation state. Only the $\mathrm{Sb}^{5+}$-substituted materials appear to have a slightly lower average Ir oxidation state, but within the errors of determining edge position it is not clear that this has physical significance, even though it may be expected by inclusion of a +5 substituent.

The crystallite domain size for the B-site substituted materials shows little dependence on composition, although most present smaller particle sizes compared to the parent phase prepared under comparable conditions at $240{ }^{\circ} \mathrm{C}$ (compare Tables 2 and 3). From the B-site substituted materials, a representative material for each substituent was selected for detailed electrocatalysis studies: these have the nominal substitution level of $y=0.5$ for the $\mathrm{Sb}$, Ru and $\mathrm{Zr}$ materials and $y=0.3$ for the $\mathrm{Rh}$ material. The composition of each material was refined from Rietveld analysis of powder neutron diffraction data (ESI $\dagger$ ), yielding chemical formulae $\left(\mathrm{Ca}_{0.59} \mathrm{Na}_{0.32}\right)_{2}\left(\mathrm{Ir}_{0.5} \mathrm{Sb}_{0.5}\right)_{2} \mathrm{O}_{6} \cdot \mathrm{H}_{2} \mathrm{O}$, $\left(\mathrm{Ca}_{0.6} \mathrm{Na}_{0.32}\right)_{2}\left(\mathrm{Ir}_{0.5} \mathrm{Ru}_{0.5}\right)_{2} \mathrm{O}_{6} \cdot 0.99 \mathrm{H}_{2} \mathrm{O}, \quad\left(\mathrm{Ca}_{0.58} \mathrm{Na}_{0.30} \mathrm{Zr}_{0.12}\right)_{2}$ $\left(\mathrm{Ir}_{0.56} \mathrm{Zr}_{0.44}\right)_{2} \mathrm{O}_{6} \cdot 0.44 \mathrm{H}_{2} \mathrm{O}$ and $\left(\mathrm{Ca}_{0.58} \mathrm{Na}_{0.30}\right)_{2}\left(\mathrm{Ir}_{0.73} \mathrm{Rh}_{0.27}\right)_{2} \mathrm{O}_{6}$. $0.64 \mathrm{H}_{2} \mathrm{O}$.

\section{Application of pyrochlores in membrane electrode assemblies}

The electrocatalytic properties of the pyrochlores were studied in membrane electrode assemblies: this was to examine the new materials in a device resembling what might be used in a real application. Our recent work on some ruthenium oxide materials as electrocatalysts has shown how electrochemical studies in liquid electrolytes do not necessarily provide a guide to the behaviour in an MEA. ${ }^{32}$ The likely reason for this is that any leaching of the constituent cations from the oxide electrocatalyst may inhibit the device through interaction with the ionomer within the catalyst layer and membrane. In contrast, in simple wet electrochemical studies, any leached ions are free to enter the liquid electrolyte, even if they must pass through a thin film of ionomer to do this. Measurements were also made with a mass spectrometry analysis of the evolved gases from the MEA to observe directly oxygen production.

Table 2 B-site substituted sodium-calcium-iridate pyrochlores with composition ranges found possible and results of analysis of powder X-ray diffraction data

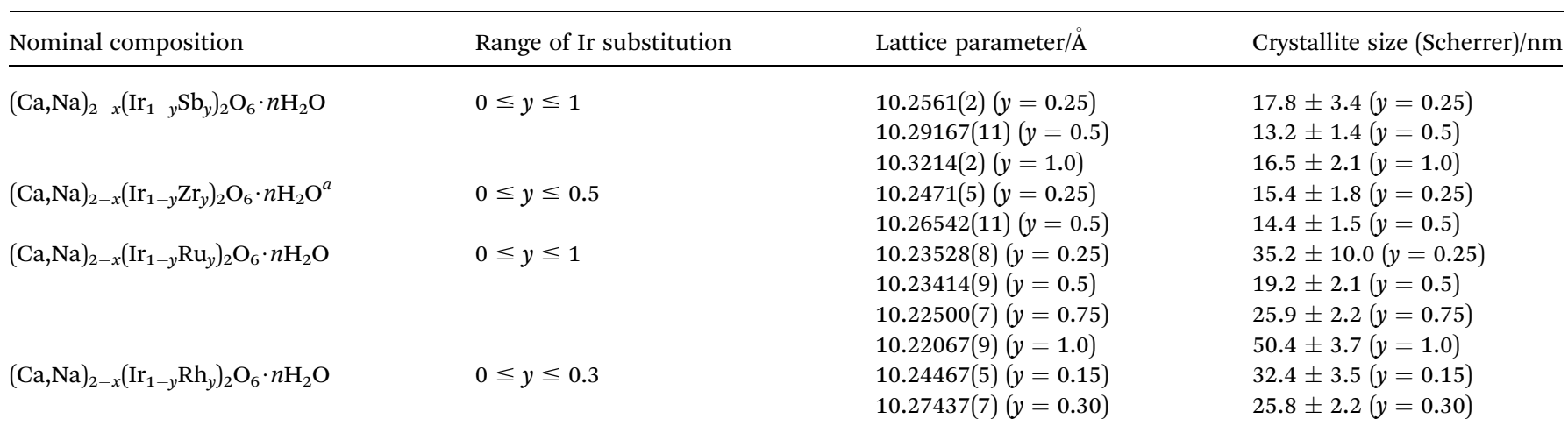

${ }^{a}$ For the $y=0.5$ zirconium-substituted material a full structural analysis showed the presence of A-site Zr as well as B-site (see text and ESI). 

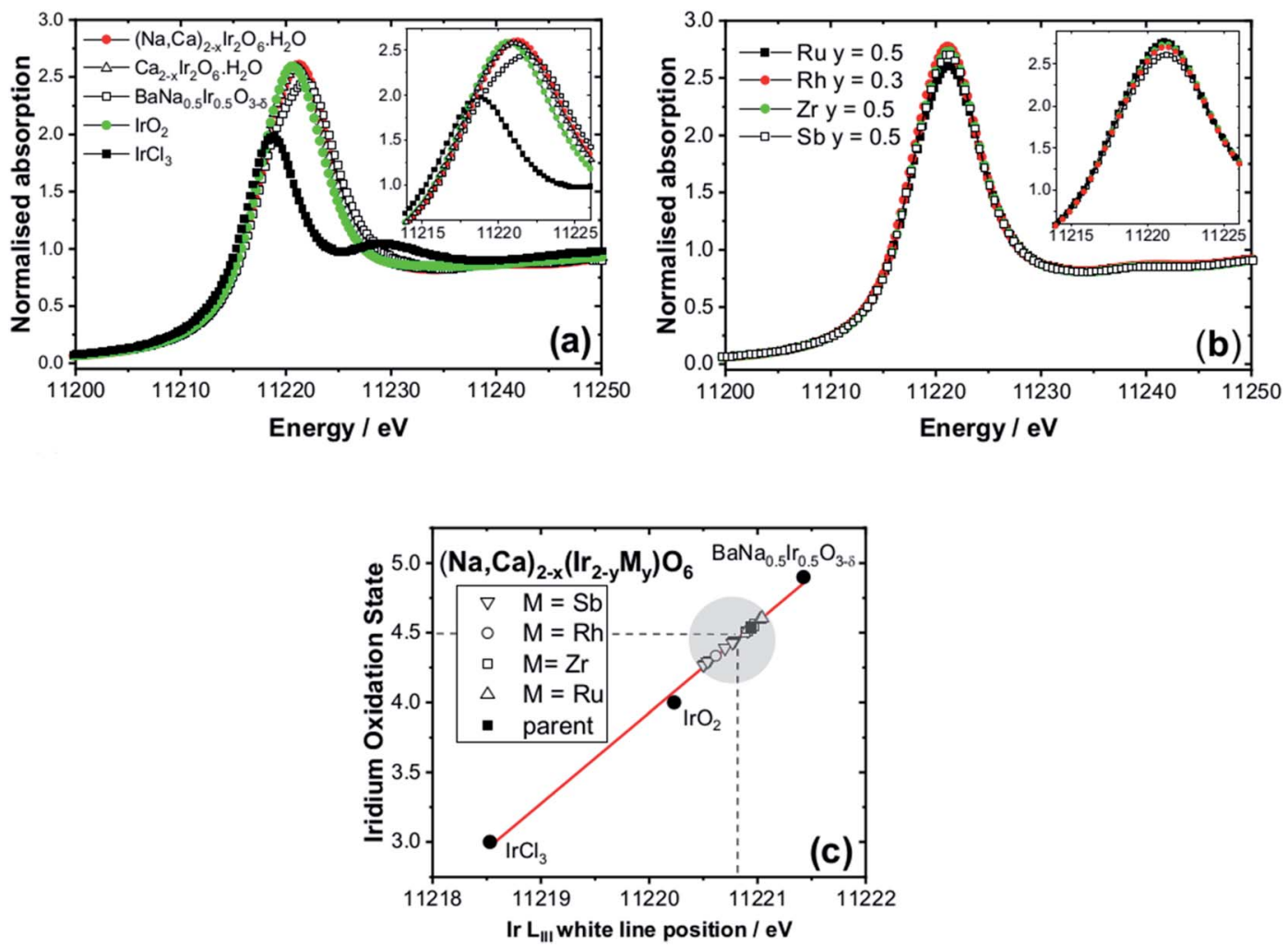

Fig. 2 Ir $\mathrm{L}_{I I I}$-edge XANES spectroscopy: (a) XANES spectra of $(\mathrm{Ca}, \mathrm{Na})_{2-x} \mid r_{2} \mathrm{O}_{6} \cdot n \mathrm{H}_{2} \mathrm{O}$ and $\mathrm{Ca}_{2-x} \mid \mathrm{r}_{2} \mathrm{O}_{6} \cdot n \mathrm{H}_{2} \mathrm{O}$ pyrochlores with reference materials where $\mathrm{BaNa}_{0.5} \mathrm{Ir}_{0.5} \mathrm{O}_{3-\delta}$ was prepared according to the literature with $\delta \approx 0.5^{, 21}$ (b) XANES spectra of $\left(\mathrm{Ca}, \mathrm{Na}_{2-x}\left(\mathrm{Ir} \mathrm{r}_{2-y} \mathrm{M}_{y}\right) \mathrm{O}_{6} \cdot n \mathrm{H}_{2} \mathrm{O}\right.$ materials and (c) analysis of the edge position to yield average oxidation state with the red line a linear fit to the reference materials and grey circle representing the scatter in edge positions of the substituted materials.

Fig. 3a shows a typical voltammogram, measured in this case from a layer formed from the small particle size $(\mathrm{Ca}, \mathrm{Na})_{2-x} \mathrm{Ir}_{2^{-}}$ $\mathrm{O}_{6} \cdot n \mathrm{H}_{2} \mathrm{O}$ pyrochlore, while Fig. $3 \mathrm{~b}$ shows the corresponding evolution of gases during galvanostatic stepping and chronopotentiometry. The voltammogram demonstrates the successful formation of a catalyst layer with the onset voltage for OER around $1.4 \mathrm{~V} v s$. standard hydrogen electrode, as desired.
In Fig. $3 \mathrm{~b}$ oxygen is produced as the applied current is increased and then held at a constant $200 \mathrm{~mA} \mathrm{~cm}{ }^{-2}$ between about 3000 seconds and 7500 seconds. After galvanostatic hold until after approximately 7500 seconds a sharp increase in cell potential is observed. This is accompanied by a rapid rise in the rate of $\mathrm{CO}_{2}$ evolution. About 500 seconds later, the rate of oxygen evolution starts to fall away at an increasing rate. The gradual oxidation of

Table 3 Membrane electrode assembly performance of pyrochlores. See text and Experimental section for definition of parameters

\begin{tabular}{|c|c|c|c|c|c|c|c|c|c|c|}
\hline \multirow[b]{2}{*}{ Pyrochlore $\mathrm{A}_{2} \mathrm{~B}_{2} \mathrm{O}_{6} \cdot x \mathrm{H}_{2} \mathrm{O}$} & \multirow{2}{*}{$\begin{array}{l}\text { BET } \\
\text { surface } \\
\text { area } \\
\left(\mathrm{m}^{2} \mathrm{~g}^{-1}\right)\end{array}$} & \multicolumn{2}{|c|}{ OER onset voltage (V) } & \multicolumn{2}{|c|}{$\begin{array}{l}\text { Mass activity }\left(\mathrm{A} \mathrm{g}^{-1}\right. \\
(\mathrm{PGM}))\end{array}$} & \multirow{2}{*}{$\begin{array}{l}\text { Cycling } \\
\text { loss } \\
(\%)\end{array}$} & \multicolumn{2}{|c|}{$\begin{array}{l}\text { Specific activity (mA } \\
\mathrm{cm}^{-2} \text { ) }\end{array}$} & \multirow{2}{*}{$\begin{array}{l}\text { Dissipated } \\
\text { charge } \\
(\mathrm{C} \\
\left.\mu \mathrm{g}^{-1}(\mathrm{PGM})\right)\end{array}$} & \multirow[b]{2}{*}{$\begin{array}{l}\mathrm{O}_{2}: \mathrm{CO}_{2} \\
\text { ratio }^{a}\end{array}$} \\
\hline & & $\begin{array}{l}\text { Before } \\
\text { cycling }\end{array}$ & $\begin{array}{l}\text { After } \\
\text { cycling }\end{array}$ & $\begin{array}{l}\text { Before } \\
\text { cycling }\end{array}$ & $\begin{array}{l}\text { After } \\
\text { cycling }\end{array}$ & & $\begin{array}{l}\text { Before } \\
\text { cycling }\end{array}$ & $\begin{array}{l}\text { After } \\
\text { cycling }\end{array}$ & & \\
\hline $\begin{array}{l}\mathrm{A}=\mathrm{Ca}, \mathrm{Na}, \mathrm{B}=\mathrm{Ir} \text { large } \\
\text { particle size }\end{array}$ & 27.2 & 1.42 & 1.42 & 1185.5 & 1820.1 & -53.5 & 4.20 & 6.45 & 31.76 & 113.9 \\
\hline $\begin{array}{l}\mathrm{A}=\mathrm{Ca}, \mathrm{Na}, \mathrm{B}=\mathrm{Ir} \text { small } \\
\text { particle size }\end{array}$ & 62.7 & 1.41 & 1.41 & 2682.1 & 3346.2 & -24.8 & 8.31 & 10.37 & 50.50 & 282.8 \\
\hline $\mathrm{A}=\mathrm{Ca}, \mathrm{Na}, \mathrm{B}=\mathrm{Ir}_{0.5} \mathrm{Sb}_{0.5}$ & 81.6 & 1.44 & 1.43 & 1775.4 & 2769.6 & -56.0 & 0.72 & 1.12 & 19.29 & 109.0 \\
\hline $\mathrm{A}=\mathrm{Ca}, \mathrm{Na}, \mathrm{B}=\mathrm{Ir}_{0.5} \mathrm{Zr}_{0.5}$ & 89.3 & 1.44 & 1.43 & 1554.0 & 2529.5 & -62.8 & 0.57 & 0.94 & 18.25 & 117.5 \\
\hline $\mathrm{A}=\mathrm{Ca}, \mathrm{Na}, \mathrm{B}=\mathrm{Ir}_{0.5} \mathrm{Ru}_{0.5}$ & 33.5 & 1.36 & 1.39 & 6628.2 & 5378.6 & 18.9 & 8.24 & 6.69 & 17.48 & 201.9 \\
\hline $\mathrm{A}=\mathrm{Ca}, \mathrm{B}=\mathrm{Ir}$ & 26.2 & 1.42 & 1.42 & 2152 & 2401.9 & -11.6 & 5.42 & 6.05 & 37.59 & 279.0 \\
\hline $\mathrm{A}=\mathrm{Ca}, \mathrm{Na}, \mathrm{B}=\mathrm{Ir}_{0.7} \mathrm{Rh}_{0.3}$ & 49.8 & 1.42 & 1.42 & 3368.0 & 4551.8 & -35.2 & 4.46 & 6.03 & 37.52 & 234.2 \\
\hline $\mathrm{Bi}_{2} \mathrm{Ir}_{2} \mathrm{O}_{7}$ & 42.0 & 1.43 & 1.42 & 4717.0 & 4744.7 & -0.6 & 28.29 & 28.46 & 26.9 & 89.8 \\
\hline
\end{tabular}

\footnotetext{
${ }^{a} \mathrm{O}_{2}: \mathrm{CO}_{2}$ ratio is directly proportional to oxygen evolution Faradaic efficiency of the electrocatalytic layer, see ESI, Section S7.
} 

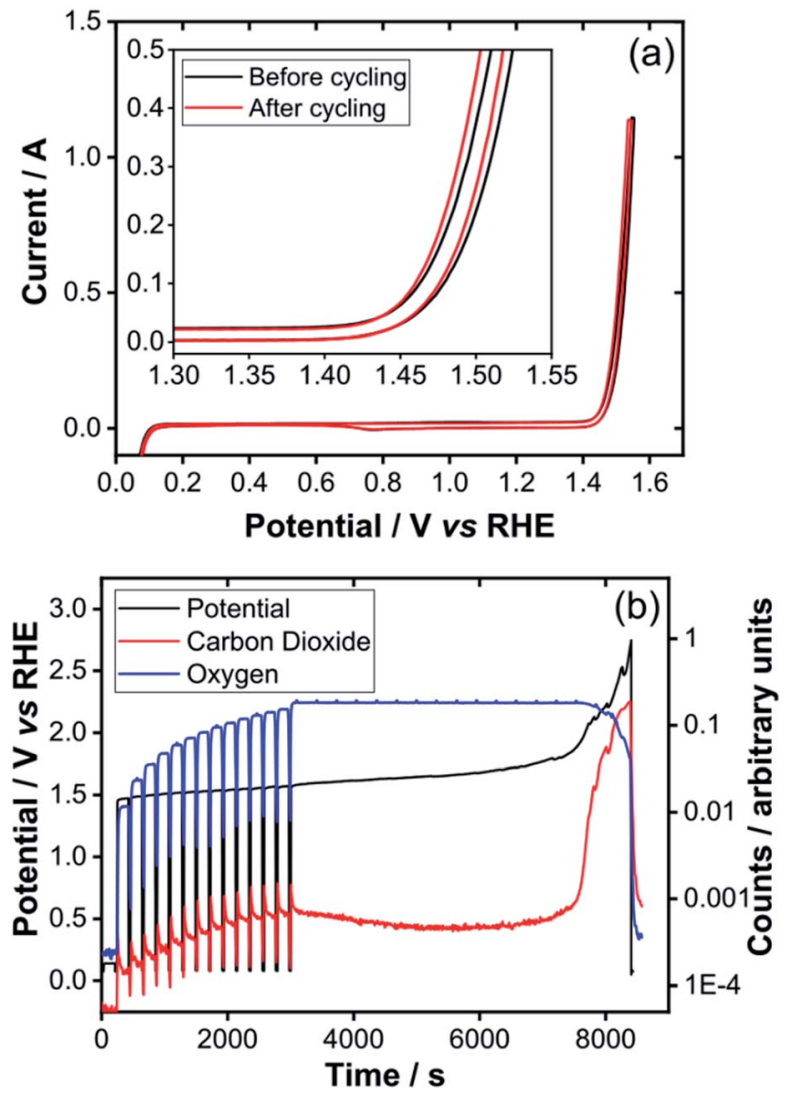

Fig. 3 (a) Cyclic voltammograms from calcium iridium oxide layer and (b) mass spectrometry results as a function of measured potential.

carbon causes increasing electrical isolation of particles of the pyrochlore such that the dominant reaction switches quite rapidly from oxygen evolution to carbon corrosion and a greater proportion of $\mathrm{CO}_{2}$ is detected in the exhaust gases. From here the carbon oxidation reaction dominates, leading to rapid degradation of the carbon components in the device. The corresponding data for other materials is provided in the ESI. $\dagger$

Table 3 contains the results from MEA studies, which also includes data from $\mathrm{Bi}_{2} \mathrm{Ir}_{2} \mathrm{O}_{7}$ for comparison. Gas evolution, activity data and Tafel slopes were derived from the cyclic voltammograms obtained before and after 500 cycles at $100 \mathrm{mV} \mathrm{s}^{-1}$ between $0.05-1.00 \mathrm{~V} v s$. reversible hydrogen electrode (RHE). The current produced at $1.5 \mathrm{~V}$ vs. RHE was normalised as activity per mass of platinum group metal (PGM, i.e. total amount of Ir, Ru or Rh). Specific activity was calculated using the catalyst mass activity normalised to the surface areas measured from nitrogen adsorption (BET method). The oxygen evolution onset potential was taken as the onset of a visible $\mathrm{O}_{2}$ signal which was $1 \mathrm{~mA} \mathrm{~cm}^{-2}$ above the background current. The total dissipated charge and $\mathrm{O}_{2}: \mathrm{CO}_{2}$ ratios are obtained from the final experiment where the layers are tested to failure. The layer was held galvanostatically for defined time steps. There were fourteen steps, the first of which drew $14.2 \mathrm{~mA} \mathrm{~cm}^{-2}$ from the layer and the last $200 \mathrm{~mA} \mathrm{~cm}{ }^{-2}$. After the final step, if the layer still had not reached the voltage cut off, the current was held until the $3 \mathrm{~V}$ cut off was reached, signalling the failure of the layer.

It should be noted that our experiments have been made under more stringent conditions than usually applied in examining the electrochemical behaviour of conducting oxides in acid solution. Typically, in simple wet electrochemical tests $0.1 \mathrm{M} \mathrm{HClO}_{4}$ is used as electrolyte and measurements are performed at room temperature, whereas we have used MEA testing at $80{ }^{\circ} \mathrm{C}$, since our objective was to study the applicability of the materials in real devices. It should be noted that the activity values we report for use in MEAs are expected to be higher than we reported from liquid cell electrochemical testing. In our recent work on ruthenium oxides using the same experimental setup we compared activities from electrochemical tests (rotating disc electrodes, RDEs) and MEA experiments, with the latter giving mass activities two orders of magnitude higher. ${ }^{32}$ Alia et al. have recently compared the behaviour of iridium oxide and iridium-metal based materials to assess how well rotating disc electrode testing predicts membrane electrode assembly performance, concluding that simple electrochemistry experiments do not replicate the activity measured under the real conditions in a device. ${ }^{33}$ Notably, Alia et al. found that RDEs kinetically underperformed MEAs by at least an order of magnitude and that durability of the catalyst in an MEA could not be estimated from the RDE performance. A portion of the activity difference may be attributable to the difference in reactant and product partial pressures for the two experimental methods, but other factors such as the behaviour of catalyst surfaces under applied conditions, and degree of catalyst dissolution are also likely to be important.

For all but one of the pyrochlore materials it is evident that an increase in activity after cycling is observed, which suggests that some chemical rearrangement of the structure takes place under the conditions used. This is consistent with the literature on various iridium oxide electrocatalysts, where leaching of cations is known to occur in acid electrolytes with applied potential, and a restructuring of the surface of the oxide particles has been proposed to yield the active catalyst layer. For example, Lebedev et al. found that for $\mathrm{Y}_{2} \mathrm{Ir}_{2} \mathrm{O}_{7}$ leaching of the $\mathrm{Y}^{3+}$ cations yielded a highly active $\operatorname{IrO}_{x}$ surface, ${ }^{23}$ and in the case of $\mathrm{IrO}_{2}$ the development of a surface hydroxyl-rich active layer was deduced by Abbot $e t$ al. ${ }^{34}$ Similar observations have been made on iridate perovskites, where a surface roughening by interaction with acid solution to give the active $\mathrm{IrO}_{x}$ catalyst. ${ }^{11,35}$ Gieger et al. proposed that defects also form in the oxide lattice upon dissolution of the non-precious metal from iridate perovskites that provide highly reactive sites for electrocatalysis. ${ }^{36}$ More recently, exchange of base-metal cations with protons has been revealed to play an important role in producing stable reactive iridium oxides surfaces for electrocatalysis, ${ }^{16,37}$ and this is an aspect that we will consider further below in the case of the new pyrochlores. As with these earlier examples, we can propose now that some restructuring of the pyrochlore surface takes place in acid solution such that electrocatalytic activity typically is improved upon electrochemical cycling. It is also relevant to note that the leaching of cations 
into the Nafion ${ }^{\mathrm{TM}}$ polymer binder is known to change the electrochemical performance of the device by modifying the proton conductivity of the ionic network. ${ }^{38}$ Leaching may occur during layer preparation and during device operation, although study of kinetics for ion mobility and leach processes are not in the scope of this work. If movement of leached cations out of the catalyst layer is faster than replenishment then apparent increased electrocatalytic activity may be expected.

The ruthenium substituted pyrochlore material has the lowest onset voltage for OER and a high activity but is the only material for which loss of activity is observed after cycling, and shows the lowest total charge dissipated. This is most likely due to the well-known solubility of ruthenium in acidic electrolytes, as has been documented for ruthenium dioxide. ${ }^{39}$ In MEAs, the loss of ruthenium into the electrolyte can have a detrimental effect on the operation of a device, as has been documented in direct methanol fuel cells where dissolution of the anode can lead to transport of ruthenium to the cathode, limiting performance and lifetime. ${ }^{40}$

Sun et al. recently proposed that local coordination geometry of the octahedral $\left\{\mathrm{IrO}_{6}\right\}$ units in solid oxides could affect OER activity, with increasing local distortion broadening $\mathrm{Ir} 5 \mathrm{~d}$ and $\mathrm{O}$ $2 \mathrm{p}$ bands leading to greater specific activities. ${ }^{22}$ Thus the pyrochlore $\mathrm{Pb}_{2} \mathrm{Ir}_{2} \mathrm{O}_{6.5}$ with irregular $\left\{\mathrm{IrO}_{6}\right\}$ octahedra was more active than $\mathrm{IrO}_{2}$ with compressed $\left\{\mathrm{IrO}_{6}\right\}$ units, which in turn is more active than $\mathrm{Bi}_{2} \mathrm{Ir}_{2} \mathrm{O}_{7}$ with regular $\left\{\mathrm{IrO}_{6}\right\}$ octahedra. The regularity of the $\left\{\mathrm{IrO}_{6}\right\}$ units in the pyrochlore structure is essentially defined by the $x$ coordinate of the $48 \mathrm{f}$ oxygen (see Table 1 , for example). For all of our materials, the $x$ coordinate shows little variation: it ranges from 0.323 (for $\mathrm{Ru}$ and $\mathrm{Rh}$ containing materials) to 0.3330 (for the $\mathrm{Zr}$-containing materials, whose local structure is complicated by the mixing of $\mathrm{Zr}$ on both A and B sites. While it must be stressed that the Rietveld analysis models the average environment of the B-site, partially occupied by the chosen substituent metals, all of the calciumiridium pyrochlores show very similar local environments. Indeed, they are all also similar to $\mathrm{Bi}_{2} \mathrm{Ir}_{2} \mathrm{O}_{7}$ with a $48 \mathrm{f}$ oxygen coordinate of 0.326: i.e. all of these materials contain close to ideal $\left\{\mathrm{IrO}_{6}\right\}$ octahedra. Thus, for the calcium iridate pyrochlores any differences in activity compared to $\mathrm{Bi}_{2} \mathrm{Ir}_{2} \mathrm{O}_{7}$ are not due to a change in local structural distortion about Ir and other factors must be responsible.

Shang et al. found for $\mathrm{R}_{2} \mathrm{Ir}_{2} \mathrm{O}_{7}(\mathrm{R}=\mathrm{Ho}, \mathrm{Tb}, \mathrm{Gd}, \mathrm{Nd}, \mathrm{Pr})$ pyrochlores that an increase of the ionic radius of $R$ gives rise to an insulator-metal transition and a strengthened hybridisation between Ir $5 \mathrm{~d}$ and $\mathrm{O} 2 \mathrm{p}$ orbitals, promoting conductivity and enhanced covalency of Ir-O bonds to improve the OER activity, thus the optimal material was $\operatorname{Pr}_{2} \mathrm{Ir}_{2} \mathrm{O}_{7} \cdot{ }^{24}$ On the other hand Abbot et al. found that for $\mathrm{R}_{2} \mathrm{Ir}_{2} \mathrm{O}_{7}(\mathrm{R}=\mathrm{Yb}, \mathrm{Gd}, \mathrm{Nd})$ pyrochlores optimum activity was found for $\mathrm{Yb}_{2} \mathrm{Ir}_{2} \mathrm{O}_{7}$, i.e., with the smallest lanthanide cations at the A site. ${ }^{25}$ Here, the $\mathrm{Yb}$ was least dissolved in the acid electrolyte, and so it is probable that the activity of these pyrochlores is a balance of structural effects (and hence electronic structure of the solid) and the rate of dissolution of A site cations. For the pyrochlores we have studied, the unit cell parameter shows comparatively little variation, compared to the lanthanide iridates, and we are also adjusting the B-site composition so it is difficult to make direct comparisons.

Further analysis was performed to understand the mechanism of electrocatalysis. The measurement of evolved oxygen was used to derive Tafel analysis of electrochemical performance. These values were compared with the conventional Tafel analysis of current-voltage data, Fig. 4. The value of the Tafel slope has been used to infer mechanistic information about the OER process in oxides: at $25{ }^{\circ} \mathrm{C}$ values of $\sim 120 \mathrm{mV}$ $\mathrm{dec}^{-1}$ have been interpreted as arising when the first electron transfer step in a sequential reaction is rate-determining, values

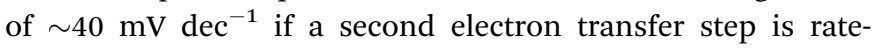
determining, and intermediate values of $\sim 60 \mathrm{mV} \mathrm{dec}{ }^{-1}$ when the rate-determining step involves a chemical step subsequent to the first electron transfer. ${ }^{41}$ For all the pyrochlores we have studied, the Tafel slope values clearly fall into the second case, with the values measured from the current plots falling between 33 and $38 \mathrm{mV} \mathrm{dec}^{-1}$, and those derived from monitoring of
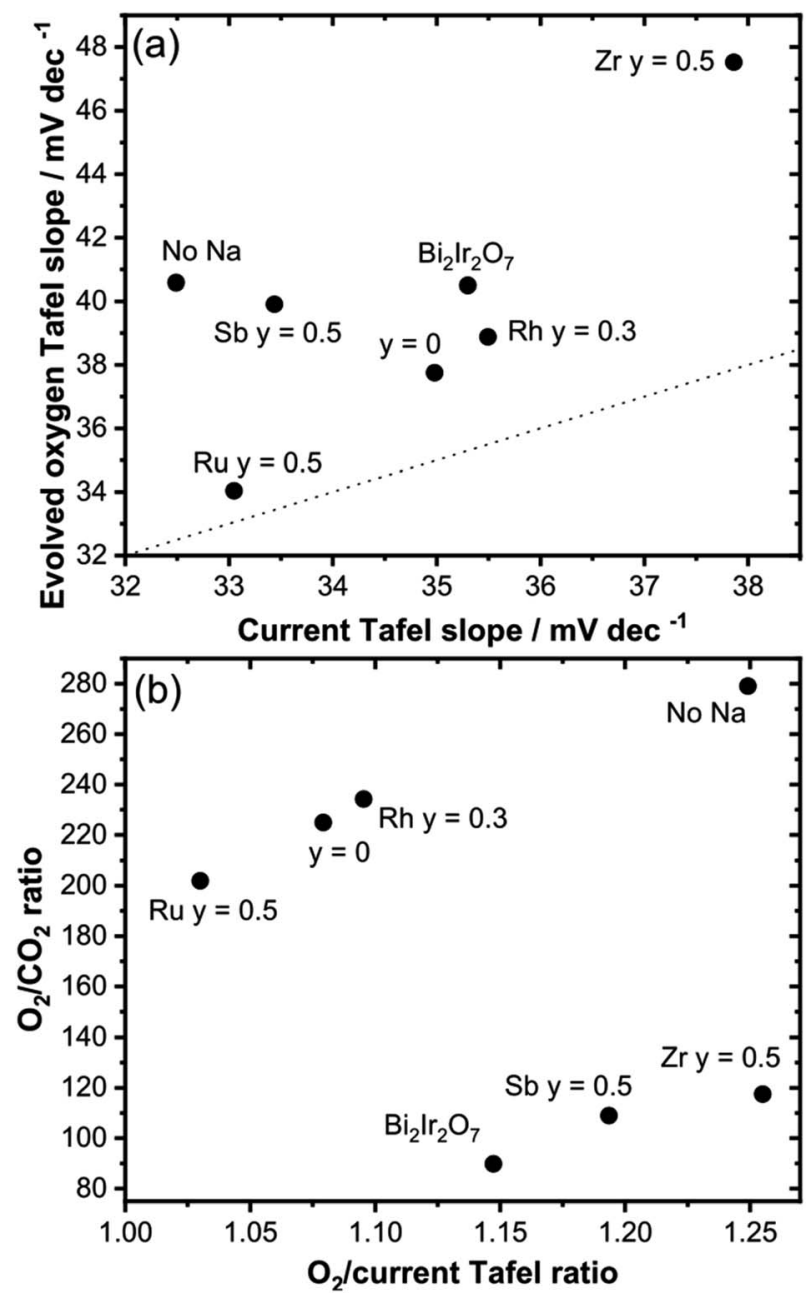

Fig. 4 (a) Tafel slope values derived from analysis of current data and from evolved oxygen for $(\mathrm{Na}, \mathrm{Ca})_{2-x}\left(\mathrm{Ir}_{2-y} \mathrm{M}_{y}\right) \mathrm{O}_{6} \cdot n \mathrm{H}_{2} \mathrm{O}(\mathrm{M}=\mathrm{Sb}, \mathrm{Zr}, \mathrm{Ru}$, $\mathrm{Rh}$ ) and $\mathrm{Ca}_{2-x} \mid \mathrm{r}_{2} \mathrm{O}_{6} \cdot n \mathrm{H}_{2} \mathrm{O}$ materials, with $\mathrm{Bi}_{2} \mathrm{Ir}_{2} \mathrm{O}_{7}$ for comparison. The dotted line is the line where the current Tafel slope = evolved oxygen Tafel slope. (b) Plot of observed $\mathrm{O}_{2} / \mathrm{CO}_{2}$ ratios against the ratio of Tafel slopes determined by the two methods for the same materials. 
evolved oxygen between 34 and $48 \mathrm{mV} \mathrm{dec}^{-1}$. Similar values have been reported for $\mathrm{IrO}_{2}$ and mixed oxides of Ir with $\mathrm{Ru}, \mathrm{Sn}$, and Ta for oxygen evolution activity where it was found that Irrich materials exhibited Tafel slopes of 30-40 mV decade ${ }^{-1} .^{42}$ Abbot et al. proposed that lower Tafel slopes indicate a hydrous surface, such as associated with surface amorphisation. ${ }^{34}$ Earlier we found a Tafel slope of $45 \mathrm{mV} \mathrm{dec}{ }^{-1}$ for $\mathrm{Bi}_{2} \mathrm{Ir}_{2} \mathrm{O}_{7}$ measured under the same electrolyte conditions. ${ }^{20}$ For other pyrochlore iridates described in the literature somewhat higher values of Tafel slope have been reported, for example $50 \mathrm{mV}$ decade ${ }^{-1}$ for $\mathrm{Y}_{2} \mathrm{Ir}_{2} \mathrm{O}_{7},{ }^{23}$ and 57-64 $\mathrm{mV} \mathrm{dec}^{-1}$ for $\mathrm{R}_{2} \mathrm{Ir}_{2} \mathrm{O}_{7}(\mathrm{R}=\mathrm{Yb}$, $\mathrm{Gd}, \mathrm{Nd}){ }^{25}$ However, those studies used $0.1 \mathrm{M} \mathrm{HClO}_{4}$ as electrolyte so the values cannot be compared directly, especially as the dissolution of the electrocatalyst may influence the measured Tafel slope, as noted by Lebedev et al. ${ }^{23}$

The deviation between the Tafel slope values measured by voltage-current and those from evolved oxygen, Fig. 4a, may be explained by additional electrochemical processes, other than oxygen evolution, taking place that lead to a lower overall Tafel slope measured electrochemically. This will include oxidation of the carbon components (carbon corrosion) and any dissolution of metal ions or other electrochemical processes. The presence of these additional processes is corroborated by the observed $\mathrm{CO}_{2}$ detected by mass spectrometry, and it is noteworthy that the materials that show the largest difference between current Tafel and evolved-oxygen Tafel, the $\mathrm{Zr}$ - and Sbsubstituted materials (and $\mathrm{Bi}_{2} \mathrm{Ir}_{2} \mathrm{O}_{7}$ ) also show the lowest $\mathrm{O}_{2}: \mathrm{CO}_{2}$ ratios in the evolved gas, Table 3 (i.e., the most carbon corrosion). Further analysis of the data makes this distinction clearer: plotted on Fig. $4 \mathrm{~b}$ is a graph of observed $\mathrm{O}_{2} / \mathrm{CO}_{2}$ ratios against the ratio of Tafel slopes determined by the two methods. This clearly divided the pyrochlores into two groups: those for which evolved $\mathrm{O}_{2} / \mathrm{CO}_{2}$ ratios are high, for which the Tafel analysis is similar for both methods, and those for which $\mathrm{O}_{2} /$ $\mathrm{CO}_{2}$ ratios are low (implying a higher degree of carbon corrosion) for which the Tafel analysis deviates between the two methods. The samples with only PGM at the pyrochlore B-site, appear to have better OER specificity, except for $\mathrm{Bi}_{2} \mathrm{Ir}_{2} \mathrm{O}_{7}$, which has a different A site cation, so it is clear that the combination of $\mathrm{A}$ and $\mathrm{B}$ cations is important in determining properties.

\section{Behaviour of the pyrochlores in acid conditions}

Having shown that iridate pyrochlores could be prepared with favourable properties for PEM device applications, we made further studies to understand their behaviour under the acidic conditions used in their application in order to understand more about the origin of their stability. The Nafion ${ }^{\mathrm{TM}}$ binder into which the electrocatalyst is dispersed provides a highly acidic environment, and we thus studied the effect of prolonged acid treatment on the $(\mathrm{Na}, \mathrm{Ca})_{2-x} \mathrm{Ir}_{2} \mathrm{O}_{6} \cdot n \mathrm{H}_{2} \mathrm{O}$ materials by immersing the materials in concentrated sulfuric acid $(\sim 18 \mathrm{M})$ for 24 hours at elevated temperature, either $80^{\circ} \mathrm{C}$ or $110{ }^{\circ} \mathrm{C}$. These are much more stringent conditions than the tests typically used for studying oxide electrocatalysts, with an acid concentration that is considerably higher and a higher temperature, but the aim was to study the ultimate acid stability of the materials. The powder XRD data from the $(\mathrm{Na}, \mathrm{Ca})_{2-x} \mathrm{Ir}_{2^{-}}$ $\mathrm{O}_{6} \cdot n \mathrm{H}_{2} \mathrm{O}$ materials show some loss of crystallinity after this acid treatment, Fig. 5, but the essential pyrochlore structure is maintained. Interestingly, the $\mathrm{Ca}_{2-x} \mathrm{Ir}_{2} \mathrm{O}_{6} \cdot n \mathrm{H}_{2} \mathrm{O}$ material showed much less change in crystallinity after acid treatment (see $\mathrm{ESI}_{\dagger}^{\dagger}$ ). The refined lattice parameters (see Fig. 5) show that the cubic unit cell contracts significantly after the acid treatment, implying a change in elemental composition. Transmission electron microscopy (TEM) images show little change

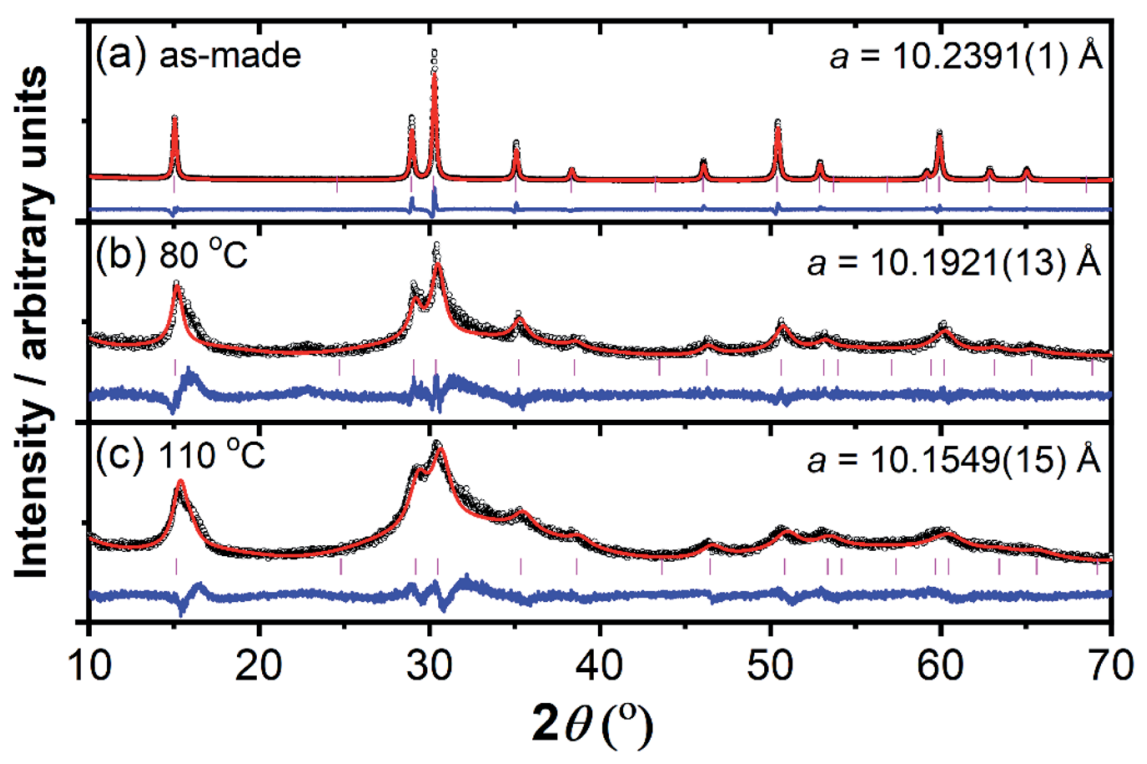

Fig. 5 Powder XRD $\left(\mathrm{Cu} \mathrm{Ka} \alpha_{1 / 2}\right)$ of $(\mathrm{Na}, \mathrm{Ca})_{2-x} \mathrm{Ir} \mathrm{r}_{2} \mathrm{O}_{6} \cdot n \mathrm{H}_{2} \mathrm{O}$ (a) as-made (b) acid-leached at $80^{\circ} \mathrm{C}$ and (c) acid leached at $110{ }^{\circ} \mathrm{C}\left(18 \mathrm{M} \mathrm{H} \mathrm{SO}_{4}\right)$. The points are the measured data, the red line the fitted profile, the blue line the difference curve and the pink ticks the positions of allowed Bragg peaks. The refined lattice parameters are given on each plot. 

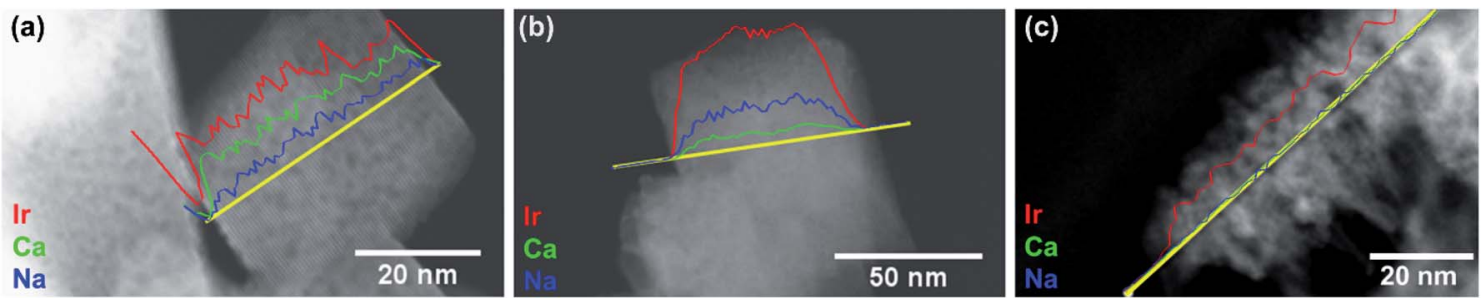

Fig. 6 TEM and EDX linescans of $(\mathrm{Na}, \mathrm{Ca})_{2-x} \mid \mathrm{r}_{2} \mathrm{O}_{6} \cdot n \mathrm{H}_{2} \mathrm{O}$ (a) as-made (b) acid-leached at $80^{\circ} \mathrm{C}$ and (c) acid leached at $110{ }^{\circ} \mathrm{C}\left(18 \mathrm{M} \mathrm{H}_{2} \mathrm{SO}{ }_{4}\right)$. The yellow lines shows the scanned areas.

in particle morphology after $80{ }^{\circ} \mathrm{C}$ treatment in acid with cubic crystallites of around $50 \mathrm{~nm}$ dimension maintained, and only after treatment at $110{ }^{\circ} \mathrm{C}$ is some loss of crystallinity apparent (ESI†). EDX line-scans performed in the TEM reveal that acid treatment results in a loss of calcium and sodium from the samples and that this occurs throughout the sample and not just at the surface, Fig. 6 . After $80^{\circ} \mathrm{C}$ treatment, around $2 / 3$ of the calcium is lost from the sample (based on quantification of the EDS signal in comparison to iridium), while the sodium remains unchanged, while after $110{ }^{\circ} \mathrm{C}$ treatment no sodium or calcium are detected in the sample. XANES analysis of these 'acid leached' samples (ESI $\dagger$ ) shows that the oxidation state of iridium is maintained at $\sim 4.5$ after the process and therefore charge must be balanced by some other mechanism. We therefore conclude that the iridate pyrochlore structure is stable under acid conditions, but that removal of the A-site $\mathrm{Na}$ and $\mathrm{Ca}$ cations occurs. The mechanism of charge balance will be considered below.

The electrochemical response of the pyrochlores after the acid leaching was also examined, which proved that the materials remain active despite the change in A-site composition, Fig. 7. Despite the extremely harsh acid pre-treatment in concentrated $\mathrm{H}_{2} \mathrm{SO}_{4}$ at $110{ }^{\circ} \mathrm{C}$ the mass activities remain larger than $1000 \mathrm{~A} \mathrm{~g}_{\mathrm{Ir}}{ }^{-1}$, and in fact were enhanced after the harshest treatment. This proves the high acid resilience of the pyrochlores as electrocatalysts.

We considered possible mechanisms by which the loss of calcium and sodium from the materials might take place, bearing in mind that the average crystal structure is maintained, as seen by powder X-ray diffraction. The pyrochlore structure is able to accommodate various ways of charge balance, including inclusion of protons, either in the form of hydroxonium ions, $\mathrm{H}_{3} \mathrm{O}^{+}$, which may occupy the $8 \mathrm{a}\left(\mathrm{O}^{\prime}\right)$ site, or the A-site positions, or by protonation of any of the oxides sites. ${ }^{17}$ To examine these possibilities as a means of charge balance we applied inelastic neutron spectroscopy (INS) to look for characteristic vibrational bands of species containing $\mathrm{O}-\mathrm{H}$, Fig. 8. To aid assignment of the measured spectrum from the iridate pyrochlore sample we also measured data from a wellcharacterised pyrochlore that is known to contain hydroxonium ions, the antimony telluride, $\left(\mathrm{H}_{3} \mathrm{O}\right) \mathrm{SbTeO}_{6}$, which contains A-site hydroxonium, a mixed B-site of $\mathrm{Sb}$ and $\mathrm{Te}$, and a vacant $\mathrm{O}^{\prime}$ site. ${ }^{43}$ Further spectral assignment was made using computation: a calculated INS spectrum for $\left(\mathrm{H}_{3} \mathrm{O}\right) \mathrm{SbTeO}_{6}$ was produced using the published crystal structure of the material, ${ }^{43}$ while for the acid-leached iridate a crystal structure model was constructed using the refined lattice parameters from neutron diffraction, as described above, with the assumption that all Ca and $\mathrm{Na}$ are removed and replaced by protons to charge balance. These protons were manually positioned as being bonded to the $48 \mathrm{f}$ oxides, bridging iridium sites, to give hydroxyl groups, as found in the pyrochlore $\left(\mathrm{H}_{2} \mathrm{O}\right)_{x} \mathrm{H}_{2} \mathrm{Ta}_{2} \mathrm{O}_{6} \cdot{ }^{29}$ The $8 \mathrm{~b}$ site was fully populated with water to give an empirical formula $\square_{2} \mathrm{Ir}_{2} \mathrm{O}_{4}(-$ $\mathrm{OH})_{2} \cdot \mathrm{H}_{2} \mathrm{O}$, corresponding to a $\mathrm{B}_{2} \mathrm{O}_{6} \mathrm{O}^{\prime}$ pyrochlore with vacant $\mathrm{A}$ site $(\square)$, B-site iridium, oxide and hydroxides in the $48 \mathrm{f}$ position and water on the $8 \mathrm{~b}\left(\mathrm{O}^{\prime}\right)$ site. The oxidation state of iridium in this model is +5 , slightly higher than the parent pyrochlore, but could be lowered in reality by the presence of any residual A-site cations.

Two configurations were considered: an ordered and a disordered version. The ordered structure is pseudosymmetric around the [011] plane. The disordered structure has protons randomly distributed throughout the structure, however, they were placed to avoid clustering around each other. The initial structures, after geometry optimisation, are shown in Fig. S6.1. $\dagger$ Both structures are initially defined with symmetry $P 1$ and retain the same symmetry after optimisation. There is a marked difference in stability: the ordered structure is more stable by $34.31 \mathrm{eV}$. Comparison of the observed and

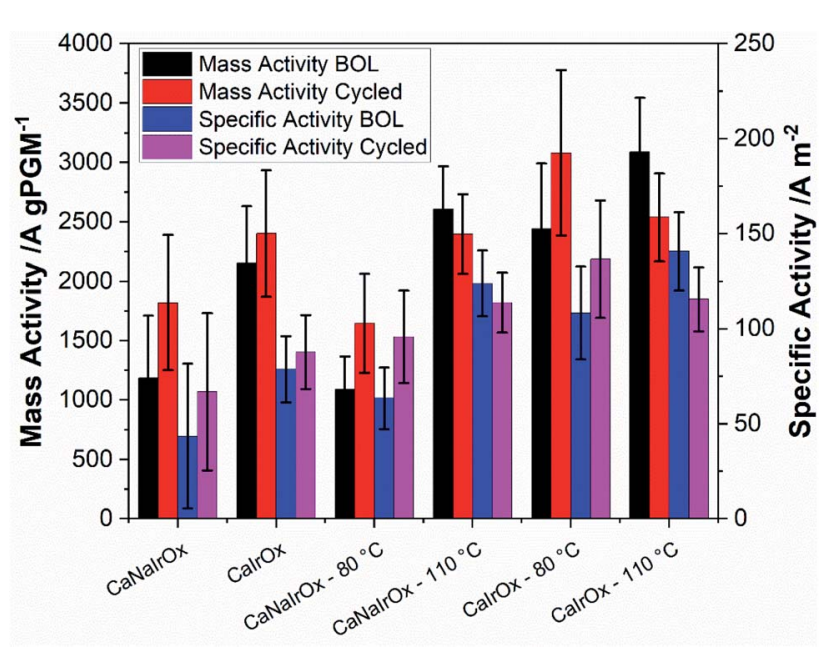

Fig. 7 Electrocatalytic performance of pyrochlores $(\mathrm{Na}, \mathrm{Ca})_{2-x} \mathrm{Ir}_{2} \mathrm{O}_{6}-$ $\cdot n \mathrm{H}_{2} \mathrm{O}$ (denoted $\mathrm{CaNalrO}_{x}$ ) and $\mathrm{Ca}_{2-x} \mathrm{Ir}_{2} \mathrm{O}_{6} \cdot n \mathrm{H}_{2} \mathrm{O}$ (denoted $\mathrm{CalrO} \mathrm{O}_{x}$ ) as-made and with acid treated, with the temperatures of acid-treatment noted. $\mathrm{BOL}=$ beginning of life. 

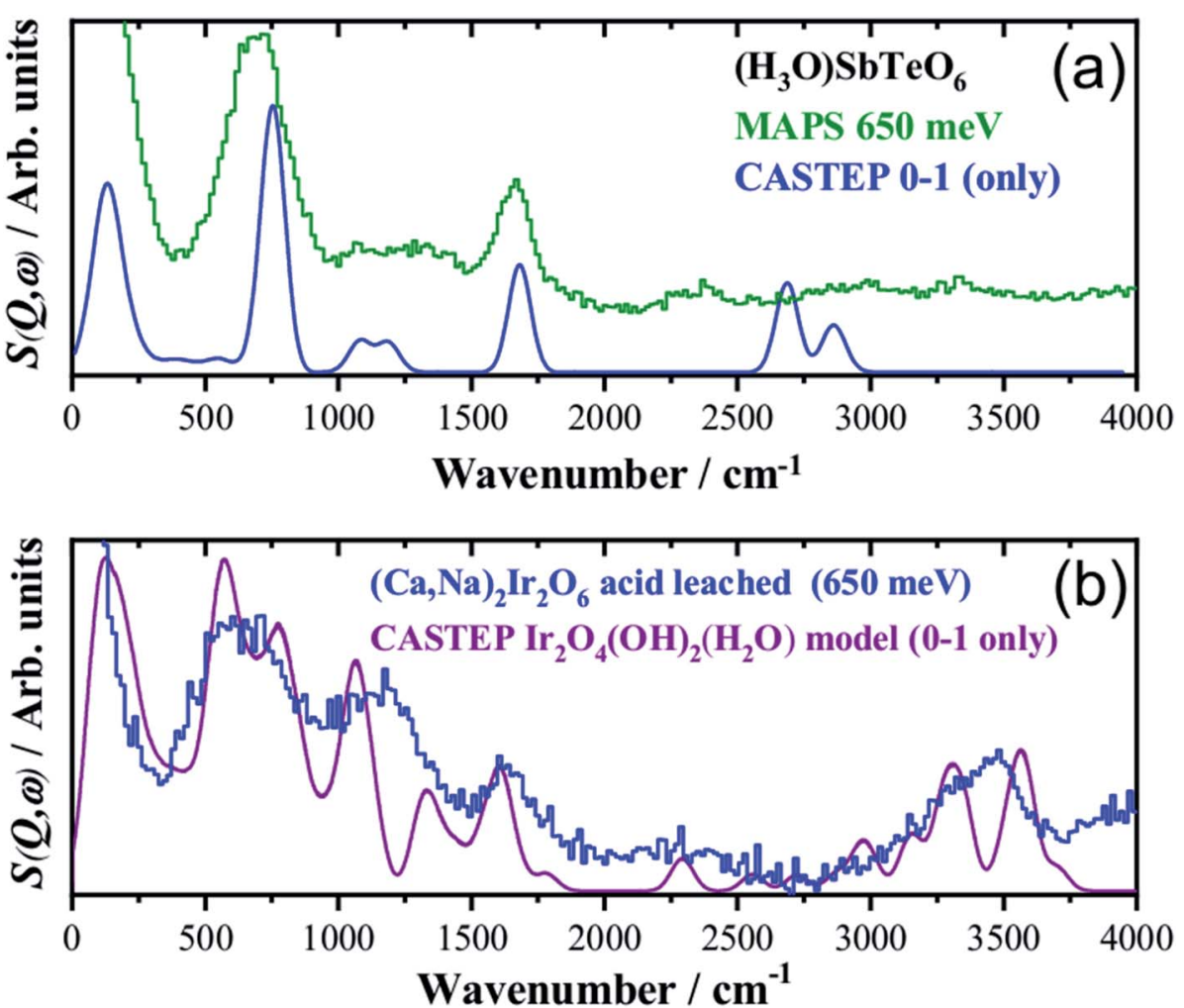

Fig. 8 Comparison of the observed and calculated INS spectra of: (a) model pyrochlore $\left(\mathrm{H}_{2} \mathrm{O}\right) \mathrm{SbTeO}_{6}$ and (b) the acid-leached ( $\mathrm{Na}$, Ca) $)_{2-x^{-}}$ $\mathrm{Ir}_{2} \mathrm{O}_{6} \cdot n \mathrm{H}_{2} \mathrm{O}$ material.

calculated INS spectra, in which the fundamental 0-to-1 transitions were considered, is a stringent test of a model and as seen in Fig. 8b the agreement with the ordered structure is very good, consistent with this being the lower energy structure (a comparison with the disordered model is shown in Fig. S6.2†). A series of models initially containing hydroxonium ions were also tested and these converged to a hydroxyl-plus-water structure in each case. This is apparent in Fig. 8, where it can clearly be seen that the spectrum of our acid-leached pyrochlore is distinctly different from that of $\left(\mathrm{H}_{3} \mathrm{O}\right) \mathrm{SbTeO}_{6}$. Table $\mathrm{S} 6.1 \dagger$ lists the observed and calculated transition energies, confirming the good agreement with the measured spectrum. Our model thus provides an explanation for how charge is balanced in the pyrochlore, even when the A-site base metal cation is leached. We can propose that the formation of hydroxyl group by protonation of bridging oxides allows charge balance.

The leaching of non-precious metals from ternary or higher iridates in acid electrolytes has now been reported for a number of materials, and is often associated with the formation of a highly active amorphous hydrated iridium oxide layer. ${ }^{23,35,44}$ The importance of structural disorder of the active phase has been established, ${ }^{45}$ but may also may lead to its ultimate instability. ${ }^{36,46}$ In more recent work it has been discovered that protonation and proton-exchange of suitable iridate structures may be the key to stabilising electrocatalytic materials. ${ }^{16,37}$ The work we have reported here corroborates this idea with the first application of inelastic neutron spectroscopy to detect the presence of charge-compensating protons.

\section{Conclusions}

Iridate pyrochlores with A-site Na or Ca provide a new family of electrocatalysts for oxygen evolution in acid electrolytes, which we have proven to remain active even after exposure to strongly acid conditions. This allows their use in membrane electrode assemblies. The compositional flexibility of the pyrochlore structure allows elemental substitution to provide a set of materials to examine trends in their electrocatalytic activity. Sodium and calcium as A-site cations allow the crystallisation of a set of pyrochlore materials with various B-site compositions, which allows the possibility of thrifting the precious metal cations by partial substitution of iridium. The pyrochlore structure is also able to accommodate loss of A-site cations, with inclusion of charge-balancing protons, and this provides stability under highly acidic conditions. Sodium and calcium as A-site cations are readily leached in aqueous acid to yield active iridium oxide phases.

From the pyrochlores studied there is no benefit in electrochemical performance upon replacement of some of the iridium by a second B-site cation. The optimal materials for application in membrane electrode assemblies are a small particle size $(\mathrm{Na}, \mathrm{Ca})_{2-x} \mathrm{Ir}_{2} \mathrm{O}_{6} \cdot n \mathrm{H}_{2} \mathrm{O}$ and the $\mathrm{Ca}_{2-x} \mathrm{Ir}_{2} \mathrm{O}_{6} \cdot n \mathrm{H}_{2} \mathrm{O}$ pyrochlore. These pure iridate pyrochlores give least loss of activity upon cycling, while the former shows the highest activity when normalised for surface area and highest total dissipated charge. These two materials also show the highest evolved $\mathrm{O}_{2}: \mathrm{CO}_{2}$ ratios, and are significantly improved over 
$\mathrm{Bi}_{2} \mathrm{Ir}_{2} \mathrm{O}_{7}$, another pyrochlore that has been studied previously as an electrocatalyst. The evolved $\mathrm{O}_{2}: \mathrm{CO}_{2}$ ratio is an important parameter in implementation of these materials in real devices, as it shows that corrosion of the carbon components, the origin of the evolved $\mathrm{CO}_{2}$, can be minimised. For example, in fuel cells the main role of this type of electrocatalyst is to prevent breakdown of the carbon when high potentials are experienced by the electrode, and instead to evolve oxygen to keep the potential below a level where rapid carbon corrosion can take place.

The inclusion of charge-balancing protons in strongly acidic conditions, such as in the ionomer binder, provide stability to the pyrochlore structure. They may conceivably play a role in the electrocatalysis itself, since protons from solution might mediate the change in iridium oxidation state with applied potential. The role of charge-balancing protons may be a general principle for optimising iridium oxide materials as active electrocatalysts, which should be a topic of further investigation. Further experimental work is also needed to understand the role of leachable ions on the interplay of stability and activity of the catalyst layers.

Finally, we note that while metrology for oxygen evolution activity is not the main focus of this work, we here highlight the importance of further investigation of this method to provide a tool for characterisation of materials in the electrochemical conversion field.

\section{Experimental section}

Pyrochlore materials were synthesised by a hydrothermal method using $\mathrm{IrCl}_{3} \cdot 5 \mathrm{H}_{2} \mathrm{O}$ (Alfa-Aesar with the water content determined accurately by TGA) in aqueous $\mathrm{NaOH}$ solution. To prepare $(\mathrm{Ca}, \mathrm{Na})_{2-x} \mathrm{Ir}_{2} \mathrm{O}_{6} \cdot \mathrm{H}_{2} \mathrm{O}, \mathrm{CaO}_{2}, \mathrm{IrCl}_{3} \cdot 5 \mathrm{H}_{2} \mathrm{O}$ and $\mathrm{Na}_{2} \mathrm{O}_{2}$ in a $1: 1: 4$ molar ratio based on $0.6 \mathrm{mmol}$ of $\mathrm{Ir}$, were added to $10 \mathrm{ml}$ of $10 \mathrm{M} \mathrm{NaOH}$ solution. The reaction was carried out in a Teflon-lined stainless steel autoclave with internal volume $\sim 20 \mathrm{~cm}^{3}$ at $240{ }^{\circ} \mathrm{C}$ for a period of 96 hours. To control the average particle size of $(\mathrm{Ca}, \mathrm{Na})_{2-x} \mathrm{Ir}_{2} \mathrm{O}_{6} \cdot \mathrm{H}_{2} \mathrm{O}$ the reaction temperature was varied between $170-240{ }^{\circ} \mathrm{C}$, with lower temperatures producing materials with smaller particle sizes (see Results and discussion). The sodium-free variant was prepared by replacement of the $\mathrm{Na}_{2} \mathrm{O}_{2}$ by $\mathrm{Li}_{2} \mathrm{O}_{2}$ and the $10 \mathrm{M}$ $\mathrm{NaOH}$ replaced by $10 \mathrm{M} \mathrm{KOH}$. To substitute iridium with other metals, a proportion of the $\operatorname{IrCl}_{3} \cdot 5 \mathrm{H}_{2} \mathrm{O}$ was partially replaced with another metal salt. Substituting iridium with antimony was possible using $\mathrm{NaSbO}_{3}$, while when substituting iridium with zirconium, ruthenium, or rhodium the chlorides (or oxychlorides) $\mathrm{ZrOCl}_{2} \cdot 8 \mathrm{H}_{2} \mathrm{O}, \mathrm{RuCl}_{3} \cdot 4 \mathrm{H}_{2} \mathrm{O}$, and $\mathrm{RhCl}_{3} \cdot 3 \mathrm{H}_{2} \mathrm{O}$, respectively, were used. It was found, however, that unless the $\mathrm{NaOH}$ concentration of the reaction was reduced to $2 \mathrm{M}$ in the ruthenium substitution reactions, a significant proportion of the metal was found to be left in solution, resulting in an orange filtrate. In all cases the solid product was recovered by suction filtration after addition to $100 \mathrm{ml}$ of deionised water to dilute the $\mathrm{NaOH}$ solution, followed by washing with $50 \mathrm{ml}$ of dilute $\mathrm{HNO}_{3}$ (approximately $3 \mathrm{M}$ ) to remove any $\mathrm{Ca}(\mathrm{OH})_{2}$ byproduct. The product was then re-washed with $20 \mathrm{ml}$ of deionised water, followed by a similar amount of acetone and dried at $80{ }^{\circ} \mathrm{C}$ in air for characterisation. The material $\mathrm{Bi}_{2} \mathrm{Ir}_{2} \mathrm{O}_{7}$ was prepared as in our previous work. ${ }^{20}$

Post synthesis removal of the alkali and alkaline earth metals from the A-site of the pyrochlore using concentrated $\mathrm{H}_{2} \mathrm{SO}_{4}$, 98\% (approximately $18 \mathrm{M}$ ) was investigated. This was achieved by adding $500 \mathrm{mg}$ of either $(\mathrm{Ca}, \mathrm{Na})_{2-x} \mathrm{Ir}_{2} \mathrm{O}_{6} \cdot \mathrm{H}_{2} \mathrm{O}$ or $\mathrm{Ca}_{2-x} \mathrm{Ir}_{2}-$ $\mathrm{O}_{6} \cdot \mathrm{H}_{2} \mathrm{O}$ to $10 \mathrm{ml}$ of conc. $\mathrm{H}_{2} \mathrm{SO}_{4}$, then stirring the suspension and heating it to either 80 or $110{ }^{\circ} \mathrm{C}$ for 18 hours.

The material $\left(\mathrm{H}_{3} \mathrm{O}\right) \mathrm{SbTeO}_{6}$ was prepared according the literature. $^{43}$

Powder XRD was used as a preliminary check of sample identity and purity before more detailed studies were carried out, with data measured at room temperature using a Siemens D5000 diffractometer operating with $\mathrm{Cu} \mathrm{K} \alpha_{1 / 2}$ radiation in Bragg-Brentano mode with samples pressed into silicon plates. Powder XRD patterns for structure refinement were recorded at room temperature using a Panalytical X'Pert Pro MPD operating with monochromatic $\mathrm{Cu} \mathrm{K}_{\alpha 1}$ radiation and equipped with a PIXcel solid-state detector. Data were analysed using the Le Bail method, using the GSAS software visualised using the EXPGUI interface, to allow Rietveld refinement of structural models. $^{42}$

Neutron diffraction data were collected using the GEM instrument at ISIS, ${ }^{47}$ the UK's neutron spallation facility. After normalisation, Bragg scattering data were analysed using the GSAS software, visualised using the EXPGUI interface, to allow Rietveld refinement of structural models. ${ }^{48}$

XANES spectroscopy was performed to provide a fingerprint of oxidation state of constituent metals in the mixed-oxide materials. Data were measured on Beamline B18 of the Diamond Light Source, UK. ${ }^{49}$ from samples diluted with an appropriate amount of polypropylene powder and pressed into self-supporting pellets. The reference materials $\mathrm{IrO}_{2}$ and $\mathrm{IrCl}_{3}$ were used as supplied by Johnson Matthey, while $\mathrm{BaNa}_{0.5} \mathrm{Ir}_{0.5^{-}}$ $\mathrm{O}_{3-\delta}$ with $\delta \approx 0.5$ was prepared as in our previous work. ${ }^{21}$

TEM was used to examine the crystal morphology and obtaining energy dispersive X-ray (EDX) spectra, maps and line scans on individual particles. Micrographs were collected on either a JEOL 2100 TEM or a JEOL ARM200F TEM, both operating at $200 \mathrm{kV}$ using $\mathrm{LaB}_{6}$ and field emission electron sources, respectively. Samples were prepared by sonication in methanol followed by dropwise deposition on $3 \mathrm{~mm}$ lacy carbon grids supplied by Agar.

Elemental mapping and EDX line scans were collected on a JEOL ARM200F equipped with an Oxford Instruments 100 $\mathrm{mm}^{2}$ windowless detector to examine the distribution of elements in selected materials. Line scan data were normalised for each element under investigation.

Surface area measurements were carried out using a Micromeritics Tristar 3000 porosimeter with samples degassed under flowing nitrogen at $200{ }^{\circ} \mathrm{C}$ for 12 hours. The surface area was calculated from the adsorption isotherms using BrunauerEmmett-Teller (BET) theory.

Thermogravimetric analysis (TGA) combined with differential scanning calorimetry (DSC) was used to probe the thermal decomposition and water and/or hydroxide content of the 
synthesised oxides and reagents used in their synthesis. Data were collected using a Mettler-Toledo TGA/DSC1 instrument fitted with a Hiden mass spectrometer to monitor the exhaust gases. 10-40 $\mathrm{mg}$ of each sample was heated in an alumina crucible with heating profiles as shown in the data presented below.

Inelastic neutron scattering (INS) spectra were recorded from selected samples using the MAPS ${ }^{50}$ instrument at ISIS. Incident energies of $650 \mathrm{meV}$ (to observe the $\mathrm{O}-\mathrm{H}$ stretch region) and 300 $\mathrm{meV}$ (to observe the $\mathrm{O}-\mathrm{H}$ deformations and the water librational modes) were used. The plane wave pseudopotential based program CASTEP was used for the calculation of the vibrational transition energies and their intensities. ${ }^{51}$ The generalised gradient approximation (GGA) Perdew-Burke-Ernzerhof (PBE) functional was used in conjunction with on-the-fly generated norm-conserving pseudopotentials with a plane-wave cut-off of $610 \mathrm{eV}$ and a Monkhorst-Pack grid of $4 \times 4 \times 4$ (32 k-points). The initial structures for the Ir-based materials were those determined in this work and shown in Fig. S6.1. $\dagger\left(\mathrm{H}_{3} \mathrm{O}\right) \mathrm{SbTeO}_{6}$ was modelled as $\left(\mathrm{H}_{3} \mathrm{O}\right) \mathrm{TeO}_{6}$ in $\mathrm{P}_{1} 32$ because it is not possible to calculate vibrational spectra with atoms that have partial occupancies. In this case a cut-off of $830 \mathrm{eV}$ and a $6 \times 6 \times 6(10$ $k$-points) were used. As the INS spectrum is dominated by the proton motions, this approximation makes little difference to the calculated spectrum. The calculations were converged to better than $|0.005| \mathrm{eV}^{-1}$. After geometry optimisation, the vibrational spectra were calculated in the harmonic approximation using density-functional perturbation-theory. ${ }^{52}$ This procedure generates the vibrational eigenvalues and eigenvectors, which allows visualisation of the modes within Materials Studio $^{53}$ and is also the information needed to calculate the INS spectrum using the program AbINS. ${ }^{54}$ It is emphasised that the transition energies have not been scaled.

To fabricate a membrane electrode assembly, $100 \mathrm{mg}$ of oxide catalyst was added to $0.5 \mathrm{~g}$ of HiSPEC18600, a commercial platinum on carbon catalyst. Aqueous Nafion ${ }^{\mathrm{TM}}$ solution (11.92 wt\% solids, $1 \mathrm{ml}$ ) was added and was mixed in a planetary mixer for 15 seconds. Additional Nafion ${ }^{\mathrm{TM}}$ solution was added to give an ink containing $110 \mathrm{wt} \%$ Nafion ${ }^{\mathrm{TM}}$ with respect to the oxide catalyst. The ink was then shear-mixed in a planetary mixer using $5 \mathrm{~mm}$ diameter yttrium stabilised zirconia ceramic beads for 3 minutes at $3000 \mathrm{rpm}$. The ink was then stirred manually with a spatula to break up any sediment; the ink was then mixed for a further 5 minutes in the planetary mixer. The ink was screen printed onto a PTFE sheet to give a layer with an overall PGM loading of $0.05-0.15 \mathrm{mg} \mathrm{cm}^{-2}$, verified using X-ray fluorescence measurements. The layer was transferred from the PTFE sheet onto Nafion ${ }^{\mathrm{TM}} \mathrm{N} 112$ membrane at $150{ }^{\circ} \mathrm{C}$ with pressure. A Pt/C layer was transferred to the opposite side of the Nafion $^{\mathrm{TM}} \mathrm{N} 112$ membrane simultaneously in order to produce the catalyst coated membrane.

The electrode was placed between two flow field plates backed with microporous layer coated carbon paper, Toray TGP$\mathrm{H}-060$, cut to the desired size. The catalyst coated membrane was then tested at $80{ }^{\circ} \mathrm{C}$ with 10 psig of fully humidified reactant gases. 5\% hydrogen in nitrogen was supplied to the $\mathrm{Pt} / \mathrm{C}$ layer and nitrogen supplied to the oxide catalyst layer. The electrochemical surface areas of the platinum in both layers were measured via CO stripping voltammetry. Cyclic voltammograms were collected, scanning the potential from 0.02 to $1.6 \mathrm{~V} v s$. RHE at $5 \mathrm{mV} \mathrm{s}^{-1}$. The membrane electrode assembly was then cycled 500 times between 0.05 and $1.0 \mathrm{~V}$ vs. RHE at $100 \mathrm{mV} \mathrm{s}^{-1}$, to simulate ageing. The cyclic voltammograms collected between 0.02 and $1.6 \mathrm{~V} v s$. RHE at $5 \mathrm{mV} \mathrm{s}^{-1}$ were then repeated. The stability of the layers was then tested under galvanostatic control stepping, with the current level being increased in several steps until a final hold at $200 \mathrm{~mA} \mathrm{~cm}$. This current density was then maintained until the cell voltage reached $3 \mathrm{~V}$, with the cathode ( $\mathrm{Pt} / \mathrm{C}$ layer) being used as a reversible hydrogen electrode. Throughout this process the mass spectrometry signals for $m / z=2,12,32$, and 44 were recorded to indicate hydrogen, carbon monoxide mass fragment, oxygen, and carbon dioxide. To determine the evolved oxygen Tafel slope, the amount of oxygen measured during voltammetry is compared with the voltage. The voltage is $I R$ corrected and its change with decade shift in oxygen signal is determined. The OER activity for the Pt/C catalyst alone was separately measured and this had considerably lower activity, with higher onset voltage and lower current with lower stability.

\section{Conflicts of interest}

There are no conflicts to declare.

\section{Acknowledgements}

We thank Johnson Matthey and the EPSRC (University of Warwick Doctoral Training account EP/K503204/1) for providing funds for a PhD studentship for DLB. RIW thanks the Royal Society for provision of an Industry Fellowship (IF150024). We are grateful to STFC for provision of beamtime at ISIS on GEM (RB1320165) and MAPS (RB1620130), ${ }^{55}$ Diamond Light Source for XANES beamtime (SP11646 and SP8986), Dr Ronald Smith for guidance with the neutron diffraction experiment, Dr Diego Gianolio and Dr Giannantonio Cibin for their assistance with running the XANES experiments, Mr David Hammond for TGAMS experiments and Dr Daniel Cook for measurement of some nitrogen adsorption isotherms. Some of the equipment used in this work was provided by the University of Warwick's Research Technology Platforms. The research data underpinning this article can be accessed at: http://wrap.warwick.ac.uk/159832.

\section{References}

1 J. J. Song, C. Wei, Z. F. Huang, C. T. Liu, L. Zeng, X. Wang and Z. C. J. Xu, Chem. Soc. Rev., 2020, 49, 2196-2214.

2 (a) Z. W. Lei, T. Y. Wang, B. T. Zhao, W. B. Cai, Y. Liu, S. H. Jiao, Q. Li, R. G. Cao and M. L. Liu, Adv. Energy Mater., 2020, 10, 2000478; (b) Y. Zhang, X. Zhu, G. Zhang, P. Shi and A.-L. Wang, J. Mater. Chem. A, 2021, 9, 58905914; (c) L. Li, P. Wang, Q. Shao and X. Huang, Adv. Mater., 2021, 2004243.

3 M. Carmo, D. L. Fritz, J. Merge and D. Stolten, Int. J. Hydrogen Energy, 2013, 38, 4901-4934. 
4 (a) W. Gu, P. T. Yu, R. N. Carter, R. Makharia and H. A. Gasteiger, in Modeling and Diagnostics of Polymer Electrolyte Fuel Cells. Modern Aspects of Electrochemistry, ed. C. Wang and U. Pasaogullari, Springer, New York, NY, 2009; (b) T. C. Crowtz, D. A. Stevens, R. J. Sanderson, J. E. Harlow, G. D. Vernstrom, L. L. Atanasoska, G. M. Haugen, R. T. Atanasoski and J. R. Dahn, J. Electrochem. Soc., 2014, 161, F961-F968.

5 (a) N. T. Suen, S. F. Hung, Q. Quan, N. Zhang, Y. J. Xu and H. M. Chen, Chem. Soc. Rev., 2017, 46, 337-365; (b) X.-K. Gu, J. C. A. Camayang, S. Samira and E. Nikolla, J. Catal., 2020, 388, 130-140; (c) S. Back, K. Tran and Z. W. Ulissi, ACS Appl. Mater. Interfaces, 2020, 12, 3825638265 .

6 (a) R. Kötz and S. Stucki, Electrochim. Acta, 1986, 31, 13111316; (b) L. E. Owe, M. Tsypkin, K. S. Wallwork, R. G. Haverkamp and S. Sunde, Electrochim. Acta, 2012, 70, 158-164; (c) O. Kasian, S. Geiger, P. Stock, G. Polymeros, B. Breitbach, A. Savan, A. Ludwig, S. Cherevko and K. J. J. Mayrhofer, J. Electrochem. Soc., 2016, 163, F3099F3104.

7 H. Xu, S. Ci, Y. Ding, G. Wang and Z. Wen, J. Mater. Chem. A, 2019, 7, 8006-8029.

8 (a) M. Huynh, D. K. Bediako and D. G. Nocera, J. Am. Chem. Soc., 2014, 136, 6002-6010; (b) M. Huynh, C. Y. Shi, S. J. L. Billinge and D. G. Nocera, J. Am. Chem. Soc., 2015, 137, 14887-14904.

9 M. V. ten Kortenaar, J. F. Vente, D. J. W. Ijdo, S. Muller and R. Kotz, J. Power Sources, 1995, 56, 51-60.

10 J. B. Goodenough, R. Manoharan and M. Paranthaman, J. Am. Chem. Soc., 1990, 112, 2076-2082.

11 L. C. Seitz, C. F. Dickens, K. Nishio, Y. Hikita, J. Montoya, A. Doyle, C. Kirk, A. Vojvodic, H. Y. Hwang, J. K. Norskov and T. F. Jaramillo, Science, 2016, 353, 1011-1014.

12 (a) O. Diaz-Morales, S. Raaijman, R. Kortlever, P. J. Kooyman, T. Wezendonk, J. Gascon, W. T. Fu and M. T. M. Koper, Nat. Commun., 2016, 7, 12363; (b) A. Grimaud, A. Demortiere, M. Saubanere, W. Dachraoui, M. Duchamp, M. L. Doublet and J. M. Tarascon, Nat. Energy, 2017, 2, 16189.

13 Q. Zhang, X. Liang, H. Chen, W. Yan, L. Shi, Y. Liu, J. Li and X. Zou, Chem. Mater., 2020, 32, 3904-3910.

14 X. Liang, L. Shi, Y. P. Liu, H. Chen, R. Si, W. S. Yan, Q. Zhang, G. D. Li, L. Yang and X. X. Zou, Angew. Chem., Int. Ed., 2019, 58, 7631-7635.

15 L. Yang, G. T. Yu, X. Ai, W. S. Yan, H. L. Duan, W. Chen, X. T. Li, T. Wang, C. H. Zhang, X. R. Huang, J. S. Chen and X. X. Zou, Nat. Commun., 2018, 9, 5236.

16 R. Zhang, P. E. Pearce, V. Pimenta, J. Cabana, H. Li, D. Alves Dalla Corte, A. M. Abakumov, G. Rousse, D. Giaume, M. Deschamps and A. Grimaud, Chem. Mater., 2020, 32, 3499-3509.

17 M. A. Subramanian, G. Aravamudan and G. V. S. Rao, Prog. Solid State Chem., 1983, 15, 55-143.

18 D. R. Modeshia and R. I. Walton, Chem. Soc. Rev., 2010, 39, 4303-4325.

19 M. Kim, J. Park, M. Kang, J. Y. Kim and S. W. Lee, ACS Cent. Sci., 2020, 6, 880-891.
20 K. Sardar, S. C. Ball, J. D. B. Sharman, D. Thompsett, J. M. Fisher, R. A. P. Smith, P. K. Biswas, M. R. Lees, R. J. Kashtiban, J. Sloan and R. I. Walton, Chem. Mater., 2012, 24, 4192-4200.

21 K. Sardar, E. Petrucco, C. I. Hiley, J. D. B. Sharman, P. P. Wells, A. E. Russell, R. J. Kashtiban, J. Sloan and R. I. Walton, Angew. Chem., Int. Ed., 2014, 53, 10960-10964. 22 W. Sun, J. Y. Liu, X. Q. Gong, W. Q. Zaman, L. M. Cao and J. Yang, Sci. Rep., 2016, 6, 38429.

23 D. Lebedev, M. Povia, K. Waltar, P. M. Abdala, I. E. Castelli, E. Fabbri, M. V. Blanco, A. Fedorov, C. Coperet, N. Marzari and T. J. Schmidt, Chem. Mater., 2017, 29, 5182-5191.

24 C. Y. Shang, C. Cao, D. Y. Yu, Y. Yan, Y. T. Lin, H. L. Li, T. T. Zheng, X. P. Yan, W. C. Yu, S. M. Zhou and J. Zeng, Adv. Mater., 2019, 31, 1805104.

25 D. F. Abbott, R. K. Pittkowski, K. Macounova, R. Nebel, E. Marelli, E. Fabbri, I. E. Castelli, P. Krtil and T. J. Schmidt, ACS Appl. Mater. Interfaces, 2019, 11, 3774837760.

26 J. Parrondo, M. George, C. Capuano, K. E. Ayers and V. Ramani, J. Mater. Chem. A, 2015, 3, 10819-10828.

27 D. L. Burnett, E. Petrucco, A. E. Russell, R. J. Kashtiban, J. D. B. Sharman and R. I. Walton, Phys. Chem. Chem. Phys., 2020, 22, 18770-18773.

28 K. Sardar, J. Fisher, D. Thompsett, M. R. Lees, G. J. Clarkson, J. Sloan, R. J. Kashtiban and R. I. Walton, Chem. Sci., 2011, 2, 1573-1578.

29 P. G. Dickens and M. T. Weller, Solid State Commun., 1986, 59, 569-573.

30 R. D. Shannon, Acta Crystallogr., Sect. A: Cryst. Phys., Diffr., Theor. Gen. Crystallogr., 1976, 32, 751-767.

31 R. K. Pittkowski, D. F. Abbott, R. Nebel, S. Divanis, E. Fabbri, I. E. Castelli, T. J. Schmidt, J. Rossmeisl and P. Krtil, Electrochim. Acta, 2021, 366, 137327.

32 D. L. Burnett, E. Petrucco, K. M. Rigg, C. M. Zalitis, J. G. Lok, R. J. Kashtiban, M. R. Lees, J. D. B. Sharman and R. I. Walton, Chem. Mater., 2020, 32, 6150-6160.

33 S. M. Alia, M. A. Ha, G. C. Anderson, C. Ngo, S. Pylypenko and R. E. Larsen, J. Electrochem. Soc., 2019, 166, F1243F1252.

34 D. F. Abbott, D. Lebedev, K. Waltar, M. Povia, M. Nachtegaal, E. Fabbri, C. Coperet and T. J. Schmidt, Chem. Mater., 2016, 28, 6591-6604.

35 C. W. Song, H. Suh, J. Bak, H. B. Bae and S. Y. Chung, Chem, 2019, 5, 3243-3259.

36 S. Geiger, O. Kasian, M. Ledendecker, E. Pizzutilo, A. M. Mingers, W. T. Fu, O. Diaz-Morales, Z. Z. Li, T. Oellers, L. Fruchter, A. Ludwig, K. J. J. Mayrhofer, M. T. M. Koper and S. Cherevko, Nat. Catal., 2018, 1, 508515.

37 P. E. Pearce, C. Z. Yang, A. Iadecola, J. Rodriguez-Carvajal, G. Rousse, R. Dedryvere, A. M. Abakumov, D. Giaume, M. Deschamps, J. M. Tarascon and A. Grimaud, Chem. Mater., 2019, 31, 5845-5855.

38 K. Hongsirikarn, J. G. Goodwin, S. Greenway and S. Creager, J. Power Sources, 2010, 195, 7213-7220. 
39 N. Hodnik, P. Jovanovič, A. Pavlišič, B. Jovanovič, M. Zorko, M. Bele, V. S. Šelih, M. Šala, S. Hočevar and M. Gaberšček, J. Phys. Chem. C, 2015, 119, 10140-10147.

40 A. Schoekel, J. Melke, M. Bruns, K. Wippermann, F. Kuppler and C. Roth, J. Power Sources, 2016, 301, 210-218.

41 R. L. Doyle, I. J. Godwin, M. P. Brandon and M. E. G. Lyons, Phys. Chem. Chem. Phys., 2013, 15, 13737-13783.

42 R. Tunold, A. T. Marshall, E. Rasten, M. Tsypkin, L. E. Owe and S. Sunde, ECS Trans., 2010, 25, 103-117.

43 J. A. Alonso and X. Turrillas, Dalton Trans., 2005, 865-867.

44 R. H. Zhang, N. Dubouis, M. Ben Osman, W. Yin, M. T. Sougrati, D. A. D. Corte, D. Giaume and A. Grimaud, Angew. Chem., Int. Ed., 2019, 58, 4571-4575.

45 (a) J. J. Gao, C. Q. Xu, S. F. Hung, W. Liu, W. Z. Cai, Z. P. Zeng, C. M. Jia, H. M. Chen, H. Xiao, J. Li, Y. Q. Huang and B. Liu, J. Am. Chem. Soc., 2019, 141, 3014-3023; (b) E. Willinger, C. Massue, R. Schlogl and M. G. Willinger, J. Am. Chem. Soc., 2017, 139, 12093-12101.

46 K. Schweinar, B. Gault, I. Mouton and O. Kasian, J. Phys. Chem. Lett., 2020, 11, 5008-5014.
47 W. G. Williams, R. M. Ibberson, P. Day and J. E. Enderby, Phys. B, 1997, 241, 234-236.

48 A. C. Larson and R. B. V. Dreele, Los Alamos National Laboratory Report LAUR 86-748, 2000.

49 A. J. Dent, G. Cibin, S. Ramos, A. D. Smith, S. M. Scott, L. Varandas, M. R. Pearson, N. A. Krumpa, C. P. Jones and P. E. Robbins, J. Phys.: Conf. Ser., 2009, 190, 012039.

50 S. F. Parker, D. Lennon and P. W. Albers, Appl. Spectrosc., 2011, 65, 1325-1341.

51 (a) S. J. Clark, M. D. Segall, C. J. Pickard, P. J. Hasnip, M. J. Probert, K. Refson and M. C. Payne, Z. Krist., 2005, 220, 567-570; (b) K. Refson, P. R. Tulip and S. J. Clark, Phys. Rev. B: Condens. Matter Mater. Phys., 2006, 73, 155114. 52 V. Milman, A. Perlov, K. Refson, S. J. Clark, J. Gavartin and B. Winkler, J. Phys.: Condens. Matter, 2009, 21, 485404.

53 BIOVIA Materials Studio, https://www.3dsbiovia.com/ products/collaborative-science/biovia-materials-studio/.

54 K. Dymkowski, S. F. Parker, F. Fernandez-Alonso and S. Mukhopadhyay, Phys. B, 2018, 551, 443-448.

55 https://doi.org/10.5286/ISIS.E.RB1620130. 